\title{
Mentha viridis oil as a green effective corrosion inhibitor for mild steel in $1 \mathrm{M}$ HCl medium
}

\author{
J. Lazrak, ${ }^{1}$ R. Salim, ${ }^{1}$ N. Arrousse, ${ }^{1}$ E. Ech-chihbi, ${ }^{1}$ F. El-Hajjaji, ${ }^{1 *}$ \\ M. Taleb, ${ }^{1}$ A. Farah $^{2}$ and A. Ramzi ${ }^{2}$
}

${ }^{1}$ Engineering Laboratory of Organometallic, Molecular Materials and Environment, Faculty of Science, University Sidi Mohamed Ben Abdellah, Po. Box 1796, Fez, Morocco

${ }^{2}$ Laboratory of Organic and Applied Chemistry, Faculty of Science and Technology, University Sidi Mohamed Ben Abdellah, Fez, Morocco

*E-mail: el.hajjajifadoua25@gmail.com

\begin{abstract}
The Mentha spicata var. viridis L. essential oil (MVEO) was analyzed by gas chromatography (GC) and gas chromatography-mass spectrometry GC/MS, which show that it consists mainly of carvone $(45.83 \%)$, limonene $(17.80 \%)$ and 1,8-cineole $(9.02 \%)$. This oil was investigated as corrosion inhibitor for mild steel in $1 \mathrm{M} \mathrm{HCl}$ solution by the weight loss measurements, the potentiodynamic polarization (PP) and the electrochemical impedance spectroscopy (EIS) techniques. The results showed that MVEO is a good corrosion inhibitor with inhibition efficiency reached to $85 \%$ at concentration of $1 \mathrm{~g} / \mathrm{L}$. The polarization curves indicated that MVEO acted as mixed type inhibitor with anodic prevalence. The adsorption of the studied inhibitor on the mild steel surface obey Temkin isotherm and the $E_{\mathrm{a}}$ and $\Delta G_{\text {ads }}^{0}$ values confirmed a physical adsorption processes of this inhibitor. In addition, the structural and electronic properties of the major components of this oil were calculated using the density functional theory (DFT) at B3LYP/6-31G (d, p) level, in order to gain further insight into the adsorption behavior and inhibition mechanism for this plant.
\end{abstract}

Keywords: Mentha spicata var. viridis L., chromatography, EIS, corrosion inhibition, mild steel, Temkin isotherm, density functional theory.

Received: September 8, 2020. Published: December 23, 2020

doi: $\underline{10.17675 / 2305-6894-2020-9-4-25}$

\section{Introduction}

Corrosion is the degradation of metals and their alloys due to a chemical or electrochemical environment. The consequences of this phenomenon are very serious, especially, in industries: cessation of the production, replacement of corroded parts, accidents, and risks of pollution. Indeed, most organic compounds have good anticorrosive action, can be a veritable solution for this problem, particularly, in aqueous mediums. However, the majority of them are highly toxic to humans and environment. These harmful effects lead us to investigate an ecofriendly compound such us essential oils and plant extracts, which are considered as a source of green corrosion inhibitors. In this context, the inhibition effect of 
Mentha essential oil as corrosion inhibitor has been studied by some researchers [1-5]. It is a perennial plant of the Lamiaceae family, of the genus Mentha, cultivated as an aromatic plant [6]. Its essential oil is rich in carvone, giving it a fresh and mentholated scent. It has a great economic importance, especially in the aroma, perfume and pharmaceutical industries.

The present work focuses on the investigation of Mentha spicata var. viridis L. essential oil (MVEO) as corrosion inhibitor for the mild steel in molar hydrochloric acid medium using various experimental techniques: weight loss, potentiodynamic polarization curves and electrochemical impedance spectroscopy (EIS). This study was accompanied by a complementary theoretical approach using DFT/B3LYP 6-31G $(\mathrm{d}, \mathrm{p})$ basis set.

\section{Materials and methods}

\subsection{Extraction of the essential oil}

The samples of Mentha spicata var. viridis L. were collected in an experimental plot of the Faculty of Science and Technology - Sidi Mohamed Ben Abdellah University, Fez. The MVEO was achieved by hydro-distillation using Clevenger-type system. As well, the distillation of each samples lasted approximately $2 \mathrm{~h}$. For each distillation, a mixture of $200 \mathrm{~g}$ of plants was used. The average oil contents were calculated from the dry matter and expressed in $\mathrm{mL} / 100 \mathrm{~g}(\mathrm{v} / \mathrm{w})$. Moreover, the oil obtained was analyzed by gas chromatography (GC) and gas chromatography-mass spectrometry (GC-MS).

\subsection{Gas chromatography (GC) analyses}

GC analyses were performed on a Hewlett-Packard (HP 6890) gas chromatograph (FID), equipped with a HP-5 capillary column $(30 \mathrm{~m} \times 0.25 \mathrm{~mm}, 0.25 \mu \mathrm{m})$. The temperature was programmed from $50^{\circ} \mathrm{C}$ after $5 \mathrm{~min}$ initial hold to $250^{\circ} \mathrm{C}$ at $4^{\circ} \mathrm{C} / \mathrm{min}$. The carrier gas was $\mathrm{N}_{2}$ $(1.8 \mathrm{~mL} / \mathrm{min}$ ) and split mode was used (ratio: $1 / 50$, Flow: $72.1 \mathrm{~mL} / \mathrm{min})$. Temperature of injector and detector were $275^{\circ} \mathrm{C}$. Diluted samples $(1 / 50$ in methanol) of $1.2 \mu \mathrm{L}$ were injected manually.

\subsection{Gas chromatography-mass spectrometry (GC/MS) analyses}

GC/MS analyses were evaluated on Hewlett-Packard equipped with a HP-5MS (Crosslinked $5 \%$ PHME Siloxane) capillary column $(30 \mathrm{~m} \times 0.25 \mathrm{~mm}$ i.d., $0.25 \mu \mathrm{m}$ film thickness $)$ which their temperature controlled from 50 to $250^{\circ} \mathrm{C}$ at $2^{\circ} \mathrm{C} / \mathrm{min}$, coupled with a mass spectrometer (HP 5973). The carrier gas was He $(1.5 \mathrm{ml} / \mathrm{min})$ and used split mode (ratio: 1/74.7, Flow: $112 \mathrm{ml} / \mathrm{min}$ ). The components were identified by further confirming their identities MS (Library of NIST98 Spectra). The MS operating parameters were ionization voltages $70 \mathrm{eV}$, ion source temperature $230^{\circ} \mathrm{C}$ and scan mass range $35-450 \mathrm{amu}$.

\subsection{Materials}

The corrosion tests were carried out on a rectangular surface of $1 \mathrm{~cm}^{2}$ area, cut from sheets of mild steel ((wt.\%):0.09 P, 0.38 Si, 0.01 Al, 0.05 Mn, 0.21 C, 0.05 S and balance of Fe). 
The samples were initially polished with several grades of emery papers (grades 400, 600, $800,1000,1200$ and 1500), cleaned by distilled water and decreased with ethanol at hot air. The appropriate concentrations tested ranging between 1 and $0.2 \mathrm{~g} / \mathrm{L}$, were prepared by dilution of an analytical reagent grade $37 \% \mathrm{HCl}$ with bi-distilled water.

\subsection{Weight loss study}

The weight loss study was performed on rectangular steel samples (length $=2 \mathrm{~cm}$, width $=1 \mathrm{~cm}$, thickness $=0.2 \mathrm{~cm}$ ) in $1 \mathrm{M} \mathrm{HCl}$ solution at different concentrations of MVEO and immersed for 6 hours in acid solution.

The corrosion rate $\left(W_{\text {corr }}\right)$ and the inhibition efficiency $\left(\eta_{\mathrm{WL}} \%\right)$ were calculated by equations 1 and 2:

$$
\begin{gathered}
W_{\text {corr }}=\frac{\Delta m}{S t} \\
\eta_{\mathrm{WL}} \% \frac{W_{\text {corr }}-W_{\text {corr } / \mathrm{inh}}}{W_{\text {corr }}} \cdot 100
\end{gathered}
$$

where $\Delta m$ is the weight loss, $t$ the immersion time and $S$ the surface of the sample. Whereas, $W_{\text {corr }}$ and $W_{\text {corr }}$ inh are respectively the corrosion rate without and with inhibitor.

\subsection{Electrochemical study}

Electrochemical techniques were carried out in a conventional three-electrode cell connected to a Versa STAT 4 potentiostat and analyzed with VersaStudio software. The electrochemical cell contains the mild steel sample as a working electrode; the platinum electrode as an auxiliary electrode and an $\mathrm{Ag} / \mathrm{AgCl}$ as a reference electrode. Before each experience, the working electrode was immersed in the tested solution during half hour until the open-circuit potential $\left(E_{\text {ocp }}\right)$ showed steady-state.

The intensity-potential (IE) curves acquired from potentiodynamic polarization experiments were recorded $\pm 250 \mathrm{mV}$ from the open-circuit potential at $298 \mathrm{~K}$ with a scan rate of $1 \mathrm{mV} \cdot \mathrm{s}^{-1}$. Moreover, the corrosion parameters such as cathodic Tafel slope $\beta_{\mathrm{c}}$, corrosion current density $i_{\text {corr }}$, and corrosion potential $E_{\text {corr }}$ were obtained by extrapolation from cathodic Tafel linear segment [7] using Ec-Lab Express software. In addition, the electrochemical impedance experiments were realized in the frequency range domain from $100 \mathrm{kHz}$ to $100 \mathrm{mHz}$, with a small perturbation amplitude of $10 \mathrm{mV}$ peak to peak, at the open circuit potential. Furthermore, the impedance spectra were analyzed according to an appropriate equivalent circuit using ZView 2.80 simulation software and presented in Nyquist and Bode representations.

\subsection{Computational details}

In order to understand the experimental behaviour of the studied essential oil as a mild steel corrosion inhibitor in hydrochloric acid medium, quantum chemistry calculations were 
performed to evaluate the inhibition performance of the three main components of this oil, namely: carvone, limonene and 1,8-cineole. Indeed, the geometries of these three compounds were optimized, using density functional theory (DFT) at B3LYP/6-31G (d, p) [8] basis set by GAUSSIAN 09 software [9]. Accordingly, a number of quantum decriptors, such as: the energies of lowest unoccupied and molecular orbital ( $E_{\mathrm{HOMO}}$ and $\left.E_{\mathrm{LUMO}}\right)$, the energy gap $(\Delta E)$, the dipole moment $(\mu)$, the absolute electronegativity $(\chi)$, the absolute hardness $(\eta)$, the softness $\sigma$, the ionization potential $(I P)$, the electron affinity $(E A)$ and the fraction of electrons transferred $(\Delta N)$, were calculated in gas and aqueous phases [10].

\section{Results and Discussion}

\subsection{Essential oil composition}

The analysis of MVEO by GC-MS technique allowed the identification of thirty-four components, which represented $94.53 \%$ in the total of the essential oil composition. The percentages of these components are summarized in Table 1.

Table 1. Chemical compound of MVEO.

\begin{tabular}{cc}
\hline Component & $\%$ \\
\hline$\alpha$-Pinene & 1.41 \\
Camphene & 0.22 \\
Sabinene & 1.4 \\
$\beta$-Pinene & 2.02 \\
Myrcene & 1.01 \\
3-Octanol & 1.05 \\
$p$-Cymene & 0.71 \\
Limonene & 17.80 \\
1,8-Cineole & 9.02 \\
(Z)- $\beta$-Ocimene & 0.20 \\
cis-Sabinene hydrate & 1.60 \\
Linalool & 0.40 \\
cis- $p$-Menth-2-en-1-ol & 0.13 \\
cis-Limonene oxide & 0.16 \\
trans-Limonene oxide & 0.11 \\
Borneol & 0.16 \\
$\delta$-Terpineol & 0.42 \\
\hline
\end{tabular}




\begin{tabular}{|c|c|}
\hline Component & $\%$ \\
\hline 4-Terpineol & 1.36 \\
\hline$\alpha$-Terpineol & 0.51 \\
\hline Dihydrocarveol & 1.73 \\
\hline cis-Dihydrocarvone & 1.94 \\
\hline trans-Carveol & 0.46 \\
\hline cis-Carveol & 0.65 \\
\hline Pulegone & 0.36 \\
\hline Carvone & 45.83 \\
\hline Isobornyl acetate & 0.10 \\
\hline iso-Dihydrocarveol acetate & 0.26 \\
\hline$\beta$-Bourbonene & 0.91 \\
\hline$\beta$-Elemene & 0.36 \\
\hline$\beta$-Caryophyllene & 1.25 \\
\hline Germacrene D & 0.26 \\
\hline Germacrene A & 0.25 \\
\hline Spathulenol & 0.12 \\
\hline Caryophyllene oxide & 0.36 \\
\hline Total identified & 94.53 \\
\hline
\end{tabular}

The MVEO containing three products as major components, which are: the carvone (45.83\%), the limonene (17.80\%) and the 1,8-cineole $(9.02 \%)$. The chemical structures of these compounds are presented in Table 2.

Table 2. Major constituents of MVEO.

\begin{tabular}{ccc}
\hline Name & Molecular formula & Formula weight $\left(\mathbf{g} \cdot \mathbf{m o l}^{-\mathbf{1}}\right)$ \\
Carvone & $\mathrm{C}_{10} \mathrm{H}_{14} \mathrm{O}$ & 150.22 \\
\hline
\end{tabular}




\begin{tabular}{ccc}
\hline Name & Molecular formula & Formula weight $\left(\mathbf{g} \cdot \mathbf{m o l}^{\mathbf{- 1}}\right)$ \\
Limonene & $\mathrm{C}_{10} \mathrm{H}_{18} \mathrm{O}$ & \\
1,8-Cineole & & \\
\hline
\end{tabular}

\subsection{Effect of concentration}

\subsubsection{Weight loss study}

The MVEO inhibition performance were evaluated by weight loss measurement after $6 \mathrm{~h}$ of immersion at various concentrations in $298 \mathrm{~K}$. The corrosion rate and inhibition efficiency for mild steel in $1 \mathrm{M} \mathrm{HCl}$ offered by MVEO molecule are given in Table 3.

Table 3. Corrosion rate and inhibiting efficacy values of mild steel exhibited for $6 \mathrm{~h}$ in $1 \mathrm{M} \mathrm{HCl}$ at various concentrations of MVEO, at $298 \mathrm{~K}$.

\begin{tabular}{ccc}
\hline $\boldsymbol{C}_{\text {inh }}(\mathbf{g} / \mathbf{L})$ & $\boldsymbol{W}_{\text {corr }}\left(\mathbf{m g} / \mathbf{c m}^{2} \cdot \mathbf{h}\right)$ & $\boldsymbol{\eta}_{\mathbf{W L}} \%$ \\
\hline $\mathrm{HCl} 1 \mathrm{M}$ & 0.6722 & - \\
1 & 0.0957 & 85.76 \\
0.8 & 0.1464 & 78.21 \\
0.6 & 0.1629 & 75.76 \\
0.4 & 0.1779 & 73.54 \\
0.2 & 0.1952 & 70.96 \\
\hline
\end{tabular}

Table 3 shows that the inhibition efficiency increases with the MVEO concentration to attain $85.76 \%$ at optimum concentration of $1 \mathrm{~g} / \mathrm{L}$. This behaviour may be due to the increased surface area covered by the molecules adsorbed on the steel surface, which decreases the corrosive environment and their contact with the steel samples [11]. 


\subsubsection{Potentiodynamic polarisation study}

The intensity-potential curves for mild steel in $1 \mathrm{M} \mathrm{HCl}$ with and without the MVEO concentrations ranged from 0.2 to $1 \mathrm{~g} / \mathrm{L}$ at $298 \mathrm{~K}$ are shown in Figure 1 .

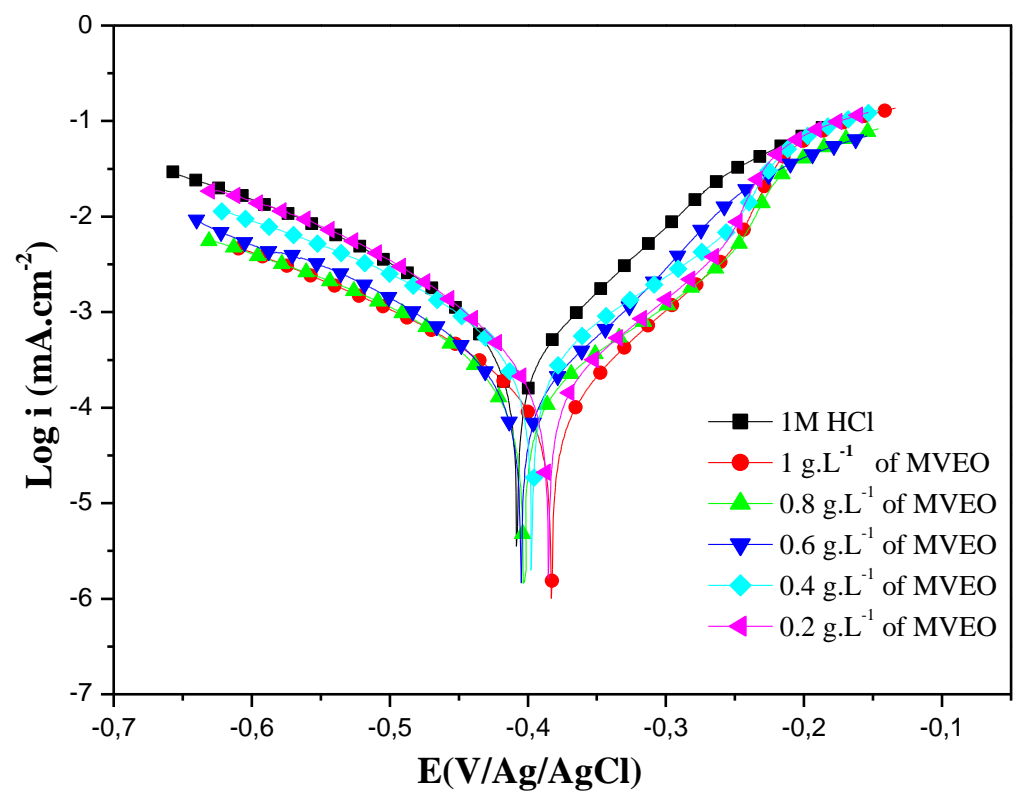

Figure 1. Intensity-potential curves of mild steel in $1 \mathrm{M} \mathrm{HCl}$ with various concentrations of MVEO at $298 \mathrm{~K}$.

It can be seen from Figure 1 that the addition of MVEO oil decreases both cathodic and anodic currents, which can be explained by the prevention of the mild steel against the acid attack. This observations suggests that the present essential oil molecules can form a protective film onto the mild steel surface $[10,12,13]$.

The cathodic branch, in the absence and presence of MVEO inhibitor are well defined Tafel lines, which means that the hydrogen evolution reaction is activation controlled. Therefore, the decrease of hydrogen ion in the cathodic area of the mild steel surface, essentially means a charge transfer mechanism $[14,15]$. The addition of MVEO to the corrosive medium leads to a small modification in the cathodic Tafel slopes $\left(\beta_{\mathrm{c}}\right)$. Indeed, the decrease observed for the cathodic area can be explained by the reduction of the surface area and therefore a reduction for the hydrogen evolution without influencing the reaction mechanism.

Besides, a slight change in the corrosion potential $\left(E_{\text {corr }}\right)$ towards the anodic branch is registered indicates that our oil inhibits both hydrogen evolution and mild steel dissolution. This displacement was less than $85 \mathrm{mV}$ which lead us to suggest that MVEO act as mixed type inhibitor [16].

Furthermore, in the anodic range for potentials above $-0.360 \mathrm{~V} / \mathrm{Ag} / \mathrm{AgCl}$, a sharp increase in the partial anodic currents were observed. This potential is called desorption potential $E_{\mathrm{d}}$ or a non-polarization potential. The increase in current density after the $E_{\mathrm{d}}$ 
potential is often interpreted by the dissolution of iron, resulting in the desorption of the inhibitor film from the electrode surface $[16,17]$.

The corrosion potential $\left(E_{\text {corr }}\right)$ values, the corrosion current density $\left(i_{\text {corr }}\right)$, cathodic Tafel slope $\left(\beta_{\mathrm{c}}\right)$ and the inhibition efficiency $\left(\eta_{\mathrm{PP}} \%\right)$ were obtained by the extrapolation of linear Tafel segments of cathodic curves and summarized in Table 4. The inhibition efficiency $\left(\eta_{\mathrm{PP}} \%\right)$ attained from potentiodynamic polarization measurements is calculated by equation 3 :

$$
\eta_{\mathrm{PP}} \%=\left(\frac{i_{\text {corr }}-i_{\text {corr/inh }}}{i_{\text {corr }}}\right)
$$

where $i_{\text {corr/inh }}$ and $i_{\text {corr }}$ are the corrosion current densities values with and without inhibitor, respectively.

Table 4. Electrochemical parameters obtained from polarization plots of mild steel in $1 \mathrm{M} \mathrm{HCl}$ with and without different concentrations of MVEO at $298 \mathrm{~K}$.

Tafel

\begin{tabular}{lccccc}
\cline { 2 - 5 } Medium & $\begin{array}{c}\boldsymbol{C}_{\text {inh }} \\
(\mathbf{g} / \mathbf{L})\end{array}$ & $\begin{array}{c}\boldsymbol{E}_{\mathbf{c o r r}} \\
(\mathbf{m V} \boldsymbol{\nu \boldsymbol { s } .} \mathbf{A g} / \mathbf{A g C l})\end{array}$ & $\begin{array}{c}\boldsymbol{i}_{\mathbf{c o r r}} \\
\left(\boldsymbol{\mu} \mathbf{A} \cdot \mathbf{c m}^{-2}\right)\end{array}$ & $\begin{array}{c}\boldsymbol{\beta} \mathbf{c} \\
\left(\mathbf{m V} \cdot \mathbf{d e c} \mathbf{- 1}^{-1}\right)\end{array}$ & $\begin{array}{c}\boldsymbol{\eta} \mathbf{P P} \\
\boldsymbol{\%}\end{array}$ \\
\hline HCl 1 M & - & -408 & 816 & -150 & - \\
\hline \multirow{3}{*}{ MVEO } & 1 & -383 & 144 & -129 & 82 \\
& 0.8 & -402 & 179 & -121 & 78 \\
& 0.6 & -403 & 211 & -115 & 74 \\
& 0.4 & -395 & 296 & -106 & 64 \\
\hline
\end{tabular}

It can be observed from Table 4 that the addition of different concentrations of MVEO leads to a considerable decrease in the current density $i_{\text {corr }}$ with the increase of MVEO concentrations. Therefore, the inhibition efficiency $\eta_{\mathrm{PP}} \%$ increases until reaches $82 \%$ at the optimum concentration of $1 \mathrm{~g} / \mathrm{L}$, indicating the formation of a more complete and stable adsorbed film onto the surface of the working electrode.

Further, the values of the cathodic Tafel slopes did not change significantly with the addition of MVEO, indicating that the mechanism of discharge of the hydrogen evolution is not affected by the inhibitor [18].

\subsubsection{EIS study}

In order to confirm the results taking out from the potentiodynamic polarization technique and to get more information on the inhibition mechanisms, the EIS measurements were performed at corrosion potential and allow to evaluate the performance of the inhibitor 
against mild steel corrosion. The Nyquist and Bode plots for mild steel in $1 \mathrm{M} \mathrm{HCl}$ solution alone and in presence of MVEO are presented respectively in Figures 2 and 3.
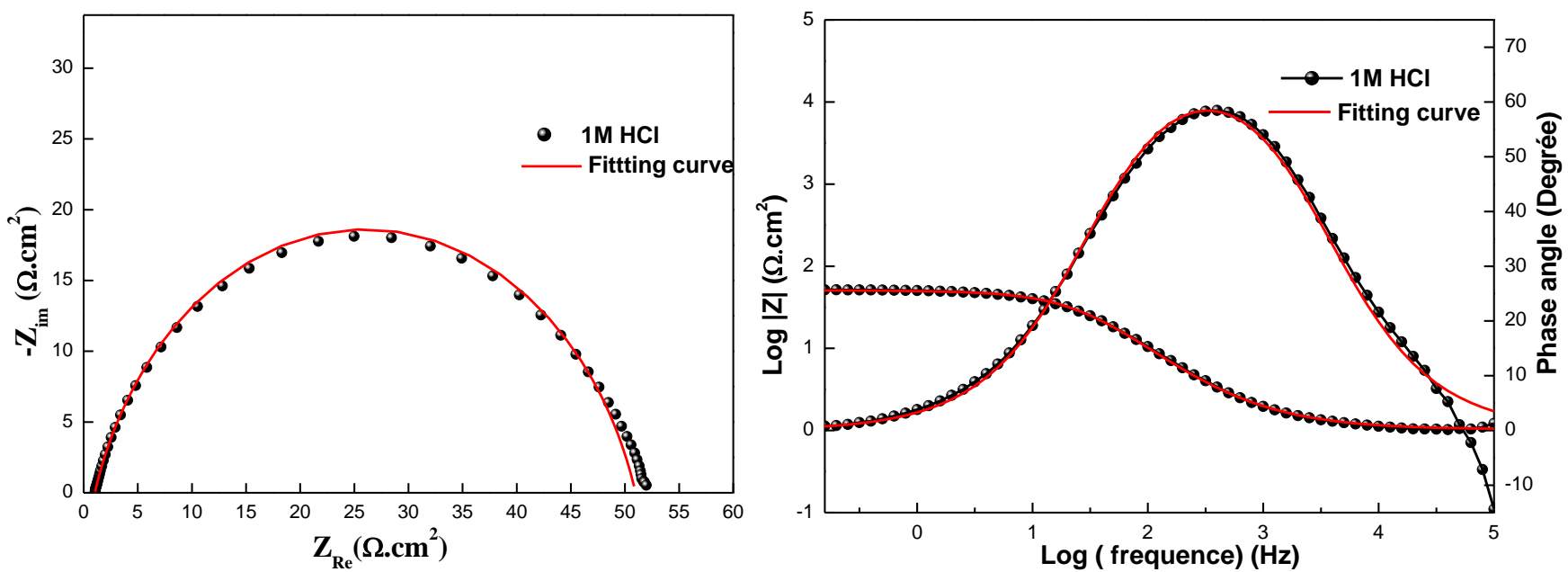

Figure 2. Nyquist and Bode diagrams of mild steel in $1 \mathrm{M} \mathrm{HCl}$ at $298 \mathrm{~K}$.
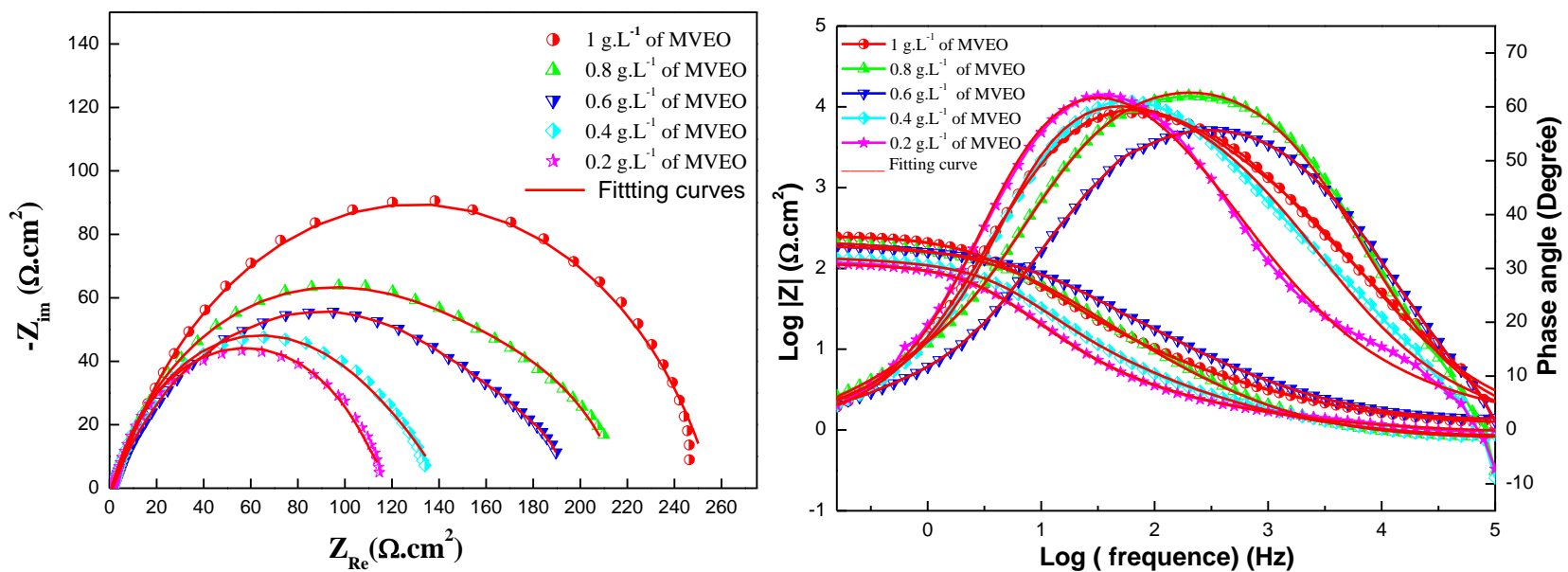

Figure 3. Nyquist and Bode diagrams of mild steel in $1 \mathrm{M} \mathrm{HCl}$ at different concentrations of MVEO.

The EIS spectra plotted for mild steel $1 \mathrm{M} \mathrm{HCl}$ presented in Figure 2, shows only one depressed capacitive loop to the higher frequency range (HF) with one capacitive time constant. In this case, the experimental impedance diagram was adapted to the appropriate equivalent model shown in Figure 4a. In this equivalent circuit, $R_{\mathrm{S}}$ is the solution resistance, $R_{\mathrm{ct}}$ present the charge transfer resistance and CPE is the constant phase element. The values of the fitted parameters are presented in Table 5.

Table 5. Fitting results of EIS data for mild steel in $1 \mathrm{M} \mathrm{HCl}$ in the absence of MVEO.

\begin{tabular}{cccccc}
\hline Medium & $\boldsymbol{R}_{\mathrm{s}}\left(\boldsymbol{\Omega} \cdot \mathbf{c m}^{2}\right)$ & $\boldsymbol{R}_{\mathrm{ct}}\left(\boldsymbol{\Omega} \cdot \mathbf{c m}^{\mathbf{2}}\right)$ & $\mathbf{C P E}\left(\boldsymbol{\mu} \mathbf{F} \cdot \mathbf{s n}^{-\mathbf{1}} \cdot \mathbf{c m}^{-\mathbf{2}}\right)$ & $\boldsymbol{C}_{\mathrm{dl}}\left(\boldsymbol{\mu F} \cdot \mathbf{c m}^{-\mathbf{2}}\right)$ & $\boldsymbol{n}_{\mathrm{dl}}$ \\
\hline $1 \mathrm{M} \mathrm{HCl}$ & $\mathbf{1 . 0 3 3}$ & 49.94 & 277.24 & 105.8 & 0.815 \\
\hline
\end{tabular}


The constant phase element (CPE) is used to replace the double layer capacitance $\left(C_{\mathrm{dl}}\right)$ in order to take into account, the heterogeneity of the electrode surface resulting from surface roughness, and thus to give a more precise fit. The impedance is given by equation 4:

$$
Z_{\mathrm{CPE}}=Q^{-1}(j \omega)^{-n}
$$

where $Q$ is proportionality coefficient of CPE $\left(\mu \mathrm{F} \cdot \mathrm{sn}^{-1}\right), n$ is an exponent associated with the phase shift, $j$ is the imaginary number and $\omega$ is the angular frequency in $\mathrm{rad} \cdot \mathrm{s}^{-1}$.

The double layer capacitance $\left(C_{\mathrm{dl}}\right)$ was determined by equation 5 :

$$
C_{\mathrm{dl}}=\left(Q R_{\mathrm{ct}}^{1-n}\right)^{1 / n}
$$
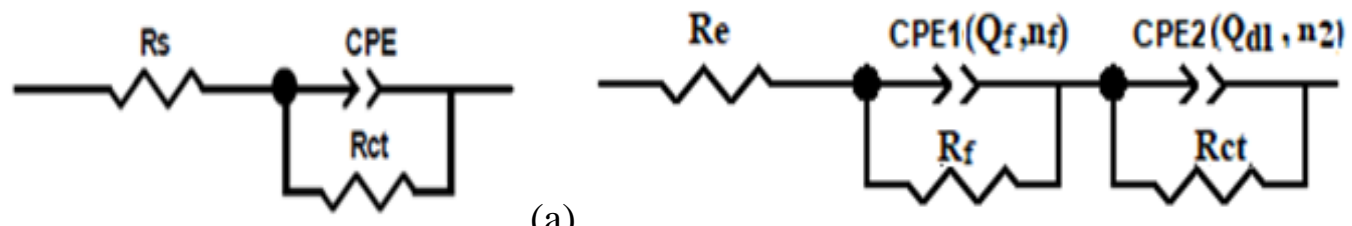

(a)

Figure 4. Equivalent circuit used to fit the impedance spectra for mild steel in $1 \mathrm{M} \mathrm{HCl}$ solution without and with MVEO.
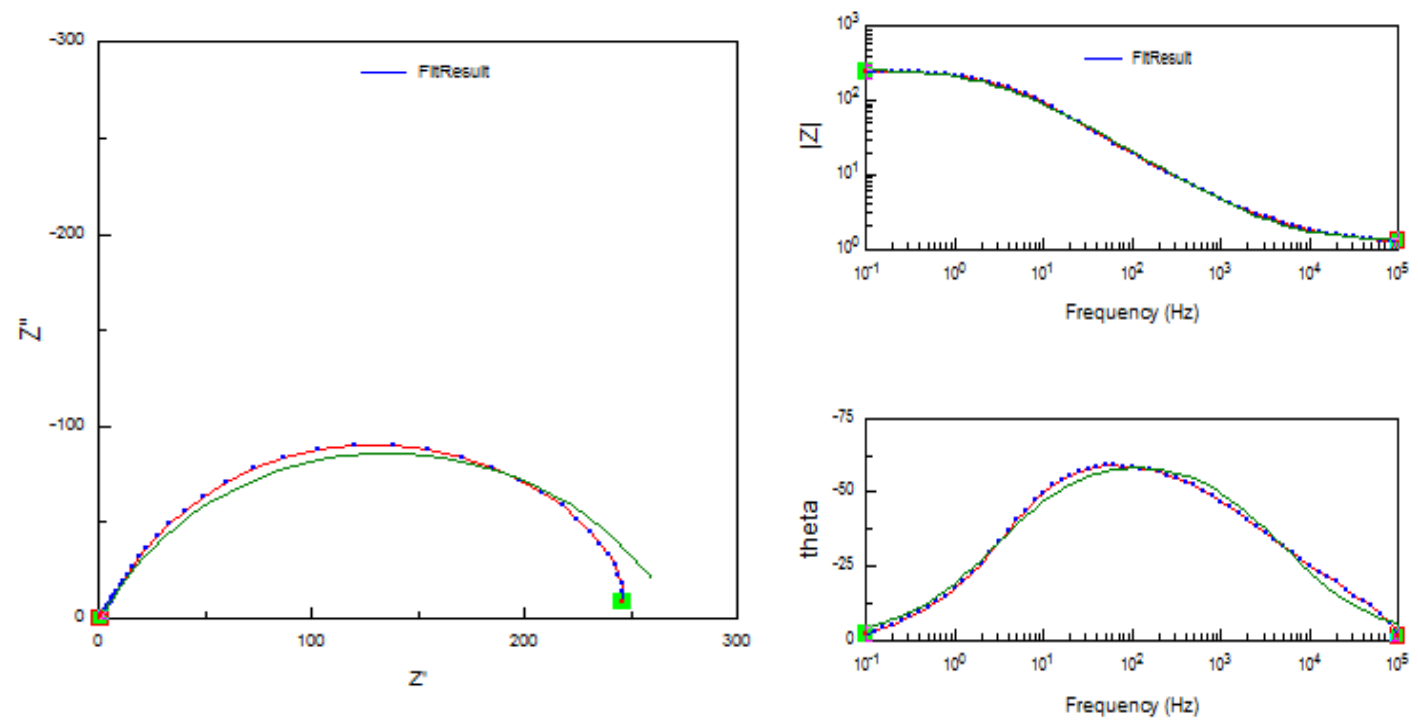

Figure 5. Nyquist and Bode diagrams for the mild steel interface in a $1 \mathrm{M} \mathrm{HCl}+1 \mathrm{~g} / \mathrm{L}$ solution in inhibitor MVEO (...) experimental curve; (-) fitted curve using structural model in Figure 4a.

To simulate the behaviour of the essential oil in $1 \mathrm{M} \mathrm{HCl}$ medium, different circuits was analysed. However, the model shown in Figure 4a does not allow a good fit of the measured data. Figure 5 shows an example of an experimental and theoretical impedance diagram in the Nyquist and Bode representation in the presence of inhibitor at the concentration of $1 \mathrm{~g} / \mathrm{L}$ (representative example) modelled by this circuit. Indeed, the 
superposition of the experimental and simulated spectrum both in the representation of Nyquist and Bode is clearly observed to be inadequate. A second time constant should, therefore, be introduced for a better simulation of the experimental data as Figure $4 \mathrm{~b}$ presented.

Figure 3 shows Nyquist plots and Bode diagrams for mild steel in $1 \mathrm{M} \mathrm{HCl}$ in the presence of a various concentrations of MVEO. The loops observed on the Nyquist diagrams in the presence of the studied inhibitor could be explained by the superposition of two-time constants, the high-frequency time constant could be attributed to the adsorption of inhibitor molecules on the steel surface, while the second time constant at low frequency could be correlated to the process of charge transfer. In addition, the diameter of the capacitive loop rises with MVEO concentration means that the inhibition performance increases as well. Figure $4 \mathrm{~b}$ represents the structural model used to describe the electrochemical impedance spectra in the presence of MVEO. As it shown in Figure 6, the experimental data were very well fitted according to this equivalent circuit. This model is valid for all MVEO concentrations and the fitted parameters are also shown in Table 6.
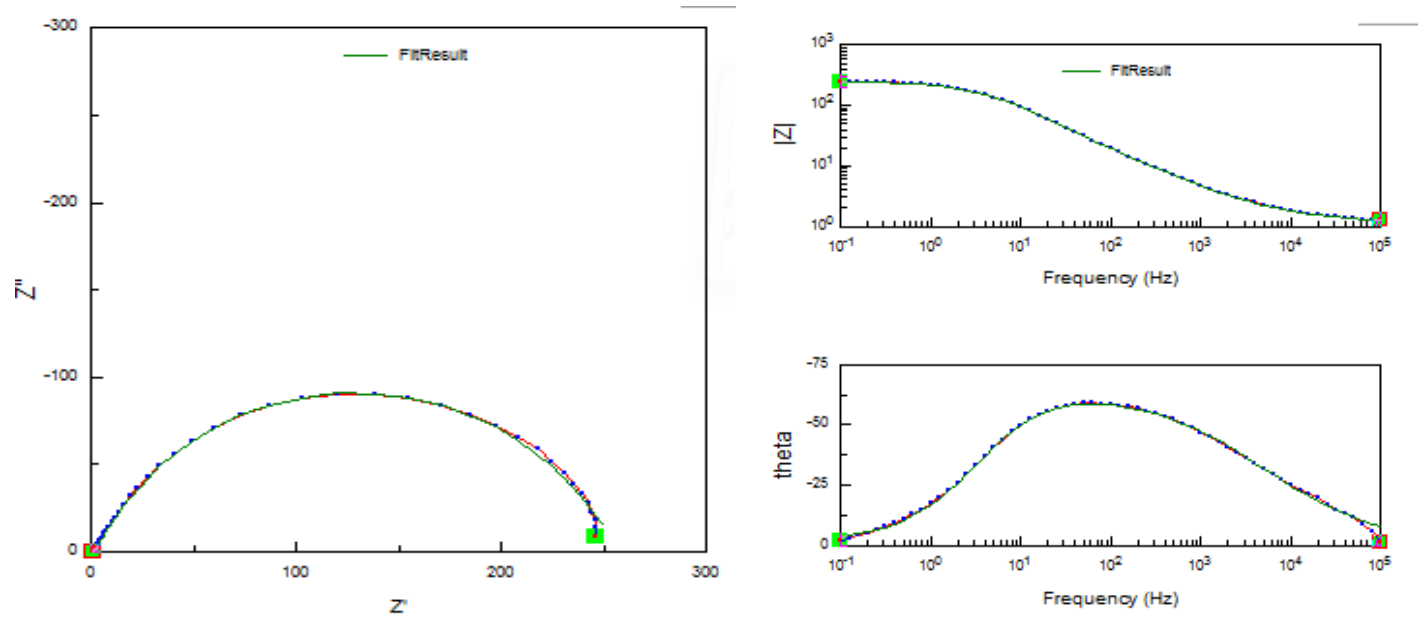

Figure 6. Nyquist and Bode diagrams for the mild steel interface in a $1 \mathrm{M} \mathrm{HCl}+1 \mathrm{~g} / \mathrm{L}$ solution in inhibitor MVEO (...) experimental curve; (-) fitted curve using structural model in Figure 4b.

The inhibitory efficacy value ( $\eta_{\text {EIS }}$ ) for the EIS measurement is calculated from the polarization resistance, using the following equation 6 .

$$
\eta_{\mathrm{EIS}} \%=\left(\frac{R_{\mathrm{p} / \mathrm{inh}}-R_{\mathrm{p}}}{R_{\mathrm{p} / \mathrm{inh}}}\right) \times 100=\theta_{\mathrm{EIS}} \times 100
$$

where $R_{\mathrm{p}}$ and $R_{\mathrm{p} / \mathrm{inh}}$ are the polarization resistance values without and with different concentrations of MVEO and $\theta_{\mathrm{EIS}}$ is the surface coverage rate. 
Table 6. Electrochemical impedance parameters of mild steel in $1 \mathrm{M} \mathrm{HCl}$ in the presence of MVEO at various concentrations at $298 \mathrm{~K}$.

\begin{tabular}{|c|c|c|c|c|c|c|}
\hline \multirow{2}{*}{$\begin{array}{l}C_{\text {inh }} \\
(\mathrm{g} / \mathrm{L})\end{array}$} & \multirow{2}{*}{$\begin{array}{c}R_{\mathrm{S}} \\
\left(\Omega \cdot \mathbf{c m}^{2}\right)\end{array}$} & \multicolumn{3}{|c|}{ CPE1 } & \multirow{2}{*}{$\begin{array}{c}R_{\mathbf{f}} \\
\left(\Omega \cdot \mathbf{c m}^{2}\right)\end{array}$} & \multirow{2}{*}{$\begin{array}{c}C_{\mathrm{f}} \\
\left(\mu \mathrm{F} \cdot \mathrm{cm}^{-2}\right)\end{array}$} \\
\hline & & \multicolumn{2}{|r|}{$\underset{\left(s^{n} \cdot \Omega^{-1} \cdot \mathbf{c m}^{-2}\right)}{Q_{\mathrm{f}}}$} & $n_{\mathrm{f}}$ & & \\
\hline 1 & 1.12 & \multicolumn{2}{|r|}{100.67} & 0.849 & 64.39 & 41.08 \\
\hline 0.8 & 0.79 & \multicolumn{2}{|r|}{170.84} & 0.779 & 50.42 & 44.50 \\
\hline 0.6 & 1.27 & \multicolumn{2}{|r|}{240.56} & 0.744 & 38.51 & 48.43 \\
\hline 0.4 & 0.80 & \multicolumn{2}{|r|}{290.96} & 0.727 & 35.24 & 52.19 \\
\hline 0.2 & 0.87 & \multicolumn{2}{|r|}{250.23} & 0.795 & 22.58 & 65.87 \\
\hline \multirow{2}{*}{$\begin{array}{l}C_{\text {inh }} \\
(\mathrm{g} / \mathrm{L})\end{array}$} & \multicolumn{2}{|c|}{ CPE2 } & \multirow{2}{*}{$\begin{array}{c}R_{\mathrm{ct}} \\
\left(\Omega \cdot \mathbf{c m}^{2}\right)\end{array}$} & \multirow{2}{*}{$\begin{array}{c}\mathrm{C}_{\mathrm{dl}} \\
\left(\mu \mathrm{F} \cdot \mathrm{cm}^{-2}\right)\end{array}$} & \multirow{2}{*}{$\begin{array}{c}R_{\mathbf{p}} \\
\left(\mathbf{\Omega} \cdot \mathbf{c m}^{2}\right)\end{array}$} & \multirow[b]{2}{*}{$\eta \operatorname{leIs}(\%)$} \\
\hline & $\underset{\left(\mathbf{s}^{n} \cdot \mathbf{\Omega}^{-1} \cdot \mathbf{c m}^{-2}\right)}{Q_{\mathrm{dl}}}$ & $n_{\mathrm{dl}}$ & & & & \\
\hline 1 & 80.35 & 0.8103 & 193.2 & 30.30 & 257.59 & 80 \\
\hline 0.8 & 102.43 & 0.7739 & 165.8 & 31.15 & 216.42 & 77 \\
\hline 0.6 & 170.25 & 0.7180 & 158.3 & 41.20 & 196.18 & 74 \\
\hline 0.4 & 200.12 & 0.7625 & 106.0 & 60.30 & 141.29 & 64 \\
\hline 0.2 & 269.53 & 0.7931 & 100.7 & 105.24 & 123.28 & 60 \\
\hline
\end{tabular}

Analysis of the calculated electrochemical parameters shows an increase in charge transfer resistance $R_{\mathrm{ct}}$ and inhibitor film resistance $R_{\mathrm{f}}$ with increasing concentration. At the same time, we observe a decrease in the pseudo-capacities related to the electrochemical double layer and the adsorption of inhibitor molecules on the surface of the metal in conjunction with the rise of inhibitory efficacy $\eta_{\mathrm{EIS}}$. This decrease of $C_{\mathrm{dl}}$ can be attributed to the formation of a protective layer on the mild steel surface [19]. In addition, the evolution of coefficients of heterogeneity shows almost the same pattern in the presence of the inhibitor studied. Indeed, the increase observed in the values of $n_{\mathrm{f}}$ and $n_{\mathrm{dl}}$ with the inhibitor concentrations can be explained with a decrease in surface heterogeneity resulting from the adsorption of inhibitors to the active sites [20].

It should be noted that the inhibitory efficiencies calculated by the EIS method are comparable and goes parallel with those obtained by weight loss measurements and potentiodynamic polarization method, indicating reasonable agreement between the two studied method. 


\subsubsection{Adsorption isotherms}

The determination of an isotherm describes the type of adsorption of a corrosion inhibitor. Therefore, it is very important to provide a significant index of the nature of the metalinhibitor interaction. The calculations in this section are based on the assumption of a blocking mechanism of action of the corrosion inhibitor. However, we have tested many adsorption isotherms such as Langmuir, El-Awady, Freundlich and Temkin. The values of the surface coverage rate $\theta_{\text {EIS }}$ are obtained by electrochemical impedance spectroscopy according to Equation 6. Indeed, all these isotherms can be defined by their linearized forms, as illustrated in Table 7 [21-26].

Table 7. The linearized forms of the most common adsorption isotherms.

\begin{tabular}{cc}
\hline Isotherms & Linear equations \\
\hline Langmuir & $\frac{C_{\text {inh }}}{\theta}=\frac{1}{K_{\text {ads }}}+C_{\text {inh }}$ \\
El-Awady & $\log \left(\frac{\theta}{1-\theta}\right)=y \log \left(K_{\text {ads }}\right)+y \log \left(C_{\text {inh }}\right)$ \\
Temkin & $\theta=\frac{-1}{2 a} \ln \left(K_{\text {ads }}\right)+\frac{-1}{2 a} \ln \left(C_{\text {inh }}\right)$ \\
Freundlich & $\ln \theta=\ln \left(K_{\text {ads }}\right)+a \ln \left(C_{\text {inh }}\right)$ \\
\hline
\end{tabular}

The standard free energy of adsorption, $\Delta G_{\text {ads }}^{0}$ was calculated according to equation 9:

$$
\Delta G_{\text {ads }}^{0}=-R T \ln \left(1000 \cdot K_{\text {ads }}\right)
$$

where $R$ is the universal gas constant, $T$ is the temperature equal to $298 \mathrm{~K}, K_{\text {ads }}$ is the equilibrium constant of the adsorption process and $1000 \mathrm{~g} / \mathrm{L}$ present the concentration of water in solution.

Figure 7 illustrate the different adsorption isotherm models using EIS technique and the adsorption parameters deduced from different isotherms and the corresponding values are recorded in Table 8.

It can be seen from Table 8 that the regression coefficient $R^{2}$ is perfectly adequate for all four isotherms. Nevertheless, the slope of the Langmuir isotherm is greater than unity (1.12) but stay the closest and reasonable isotherm to explain the adsorption process. This deviation directs us to look for another isotherm that well describes the corrosion process.

From El-Awady isotherm, the parameter deduced $1 / y$ is of the order of 1 , which implies that each active compound of the essential oil is replaced by one molecule of water fixed to an active site on the surface of the mild steel during the inhibition process. 

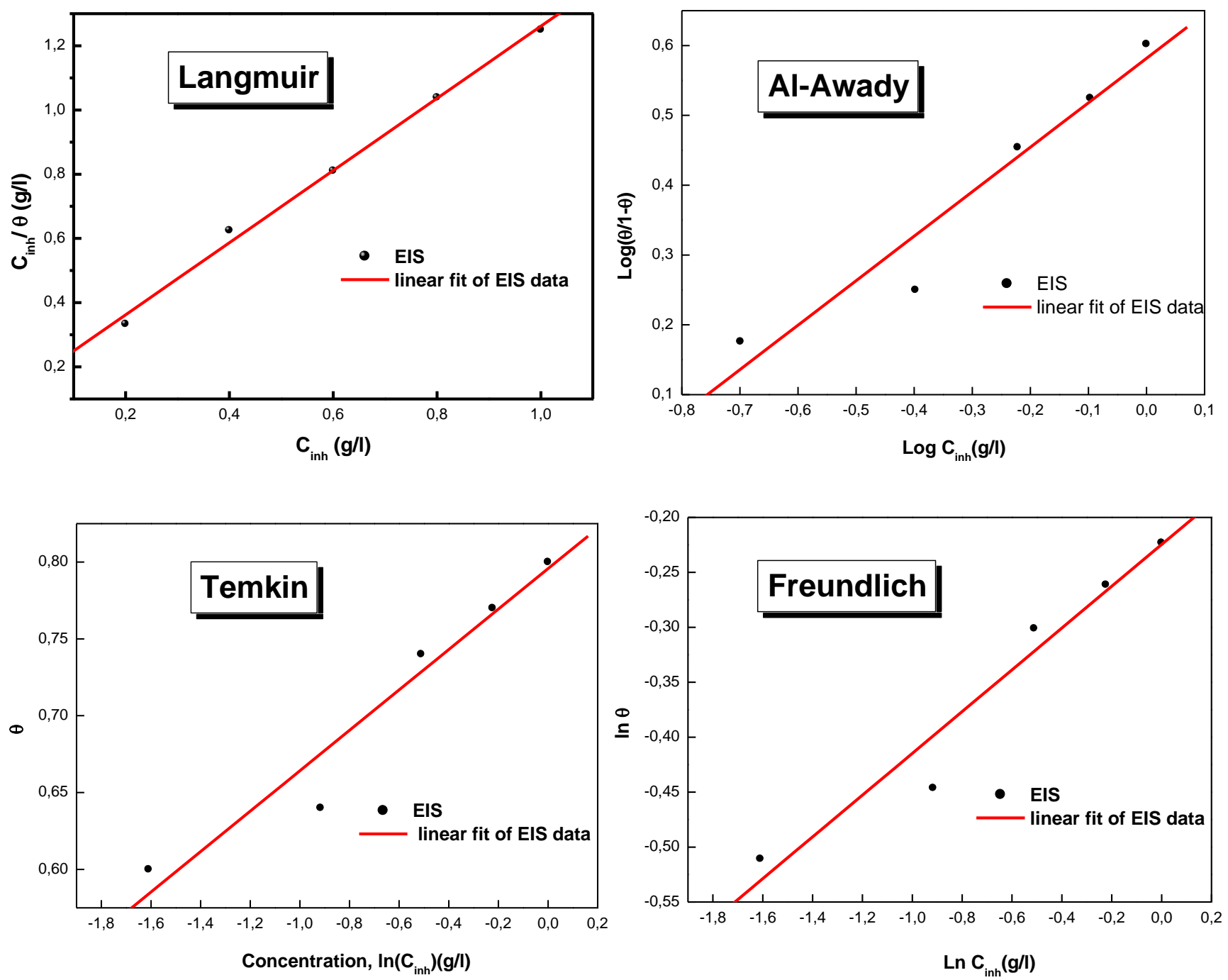

Figure 7. Plots of the adsorption isotherm models of MVEO for mild steel surface in $1 \mathrm{M} \mathrm{HCl}$ at $298 \mathrm{~K}$ obtained from EIS data.

According to Table 8, it should be noted that the $K_{\text {ads }}$ value obtained from the three isotherms is very low, except for the Temkin isotherm. Therefore, these three models are rejected, despite the high values of the coefficient of regression $R^{2}$. Consequently, it can be concluded that the adsorption process obeys the Temkin isotherm due to the high value of $K_{\text {ads }}$ and the $R^{2}$ coefficient. Also, the negative sign of the intermolecular interaction parameter between the essential oil molecules adsorbed on the mild steel surface, which suggests the existence of molecular interactions in the adsorbed layer.

Generally, when $\Delta G_{\text {ads }}^{0}$ values around $-20 \mathrm{~kJ} \cdot \mathrm{mol}^{-1}$, or less negative, the interactions between the charged mild steel surface and the charged essential oil compounds are electrostatic and the adsorption is physical. Whereas, when the values of $\Delta G_{\text {ads }}^{0}$ are close to $-40 \mathrm{~kJ} \cdot \mathrm{mol}^{-1}$ or more negative, in this case, there is a transfer of electrons from the inhibitor molecules to the surface of the metal and the adsorption is chemical $[27,28]$. According to 
the obtained results, the adsorption type of the MVEO essential oil can be adsorbed with physisorption nature.

Table 8. Adsorption parameters deduced from various adsorption isotherms of MVEO at $298 \mathrm{~K}$.

\begin{tabular}{cccccc}
\hline Isotherms & $\boldsymbol{R}^{\mathbf{2}}$ & \multicolumn{2}{c}{ Parameters } & $\boldsymbol{K}_{\text {ads }}, \mathbf{L} \cdot \mathbf{g}^{-\mathbf{1}}$ & $\Delta \boldsymbol{G}_{\text {ads }}^{\mathbf{0}}, \mathbf{k J} \cdot \mathbf{m o l}^{\mathbf{- 1}}$ \\
\hline Langmuir & 0.995 & slope & 1.12 & 7.28 & -22 \\
El-Awady & 0.937 & $1 / y$ & 1.57 & 8.19 & -22 \\
Freundlich & 0.949 & $n$ & 0.19 & 0.80 & -17 \\
Temkin & 0.944 & $a$ & -3.80 & $4.25 \cdot 10^{3}$ & -25 \\
\hline
\end{tabular}

\subsection{Immersion time effect}

The evolution of the inhibiting effect as a function of the immersion time makes it possible to have interesting information on the stability of the inhibitor film. Therefore, we evaluated the influence of this factor basing on electrochemical impedance spectroscopy results. The impedance measurements were carried out during immersion times from $0.5 \mathrm{~h}$ to $10 \mathrm{~h}$ at $298 \mathrm{~K}$.

The Nyquist diagrams versus immersion time in $1 \mathrm{M} \mathrm{HCl}$ solution in the absence and presence of $1 \mathrm{~g} / \mathrm{L}$ of MVEO at $298 \mathrm{~K}$ are shown in Figure 8.
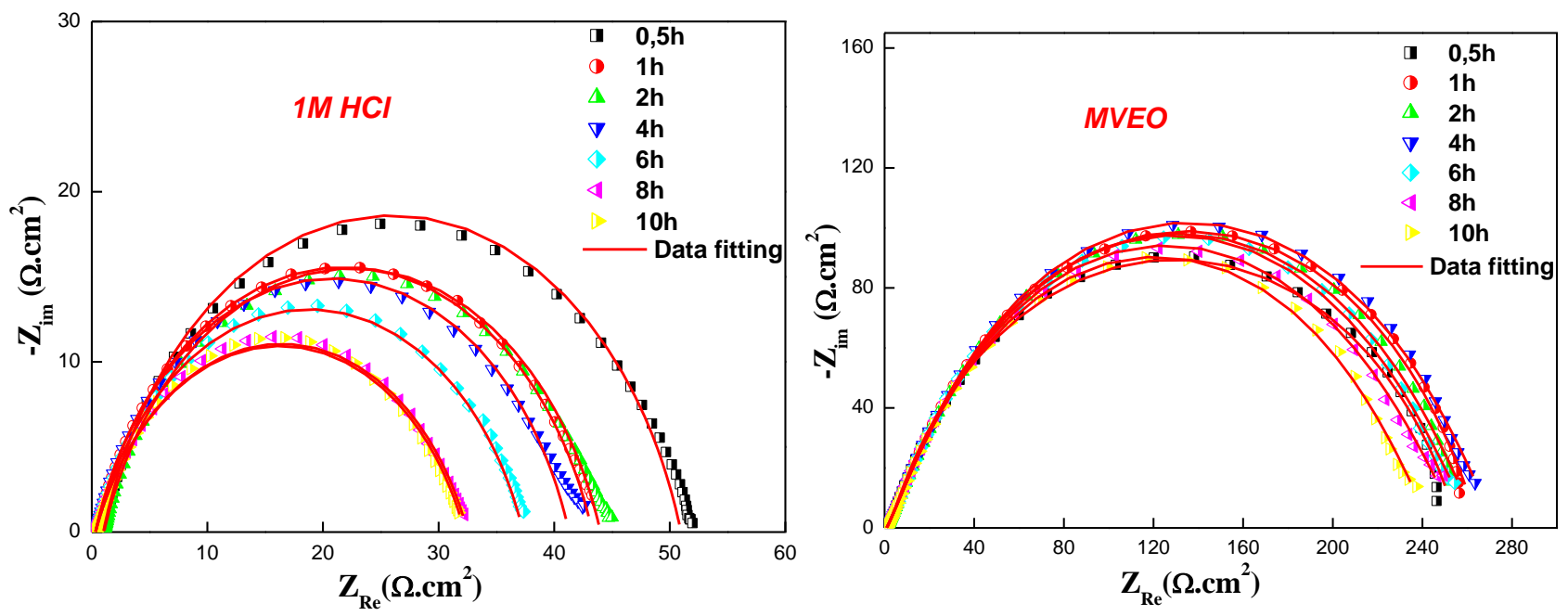

Figure 8. Impedance spectra obtained after different immersion time in $1 \mathrm{M} \mathrm{HCl}$ solution without (a) and with (b) $1 \mathrm{~g} / \mathrm{L}$ of MVEO.

According to Figure 8, it can be observed that an increase in the size of the capacitive loop up to four hours of immersion, then, beyond $4 \mathrm{~h}$, a slight decrease in the impedance spectrum diameter was recorded. This behaviour could be explained by the stability of the protective layer formed by the essential oil compounds adsorbed on the metal surface $[29,30]$. Moreover, it should be noted that a good correlation between the experimental and 
simulated data was obtained by the circuit adopted before (Figure $4 \mathrm{~b}$ ), which perfectly attests to the existence of two relaxation phenomena in the frequency domain exploited. The equivalent circuit parameters are presented in Table 9.

It is clear from Table 7 that after $4 \mathrm{~h}$ of immersion, the values of $R_{\mathrm{ct}}$ and $R_{\mathrm{f}}$ decrease while the values of $C_{\mathrm{dl}}$ and $C_{\mathrm{f}}$ increase with immersion time.

This behavior can be attributed to an increase in the film's performance up to 4 hours. As a result, it can be suggesting that a protective layer was formed on the steel surface during 4 hours [31].

Table 9. Impedance data for mild steel in the absence and presence of $1 \mathrm{~g} / \mathrm{L}$ of MVEO at different immersion periods.

\begin{tabular}{|c|c|c|c|c|c|c|c|c|}
\hline Medium & $\begin{array}{c}\text { Time } \\
\text { (h) }\end{array}$ & $\begin{array}{c}R_{\mathrm{s}} \\
\left(\boldsymbol{\Omega} \cdot \mathrm{cm}^{2}\right)\end{array}$ & $\begin{array}{c}R_{\mathrm{f}} \\
\left(\Omega \cdot \mathrm{cm}^{2}\right)\end{array}$ & $\begin{array}{c}C_{\mathrm{f}} \\
\left(\mu \mathrm{F} \cdot \mathbf{c m}^{-2}\right)\end{array}$ & $\begin{array}{c}R_{\mathrm{ct}} \\
\left(\Omega \cdot \mathrm{cm}^{2}\right)\end{array}$ & $\begin{array}{c}C_{\mathrm{dl}} \\
\left(\mu \mathrm{F} \cdot \mathbf{c m}^{-2}\right)\end{array}$ & $\begin{array}{c}R_{\mathbf{p}} \\
\left(\mathbf{\Omega} \cdot \mathbf{c m}^{2}\right)\end{array}$ & $\begin{array}{c}\text { ךEIS } \\
\%\end{array}$ \\
\hline \multirow{7}{*}{$1 \mathrm{M} \mathrm{HCl}$} & 0.5 & 1.033 & - & - & 49.94 & 105.8 & 49.94 & - \\
\hline & 1 & 0.358 & - & - & 42.96 & 331.3 & 42.96 & - \\
\hline & 2 & 1.097 & - & - & 41.93 & 333.7 & 41.93 & - \\
\hline & 4 & 0.356 & - & - & 40.94 & 347.2 & 40.94 & - \\
\hline & 6 & 0.359 & - & - & 36.97 & 409.1 & 36.97 & - \\
\hline & 8 & 0.363 & - & - & 32.16 & 562.6 & 32.16 & - \\
\hline & 10 & 0.367 & - & - & 31.90 & 663.0 & 31.90 & - \\
\hline \multirow{7}{*}{ MVEO } & 0.5 & 1.294 & 02.64 & 41.08 & 246.4 & 30.30 & 257.59 & 80.61 \\
\hline & 1.0 & 1.125 & 69.08 & 21.27 & 196.3 & 25.59 & 265.38 & 83.81 \\
\hline & 2.0 & 1.118 & 101.6 & 24.28 & 162.9 & 27.17 & 264.50 & 84.14 \\
\hline & 4.0 & 1.120 & 112.4 & 18.69 & 159.9 & 22.42 & 272.30 & 84.96 \\
\hline & 6.0 & 1.103 & 115.9 & 34.50 & 146.0 & 28.87 & 261.90 & 85.88 \\
\hline & 8.0 & 1.098 & 126.9 & 47.25 & 128.4 & 47.15 & 255.30 & 87.40 \\
\hline & 10.0 & 1.083 & 118.8 & 57.79 & 124.2 & 54.83 & 243.00 & 86.87 \\
\hline
\end{tabular}

\subsection{Temperature effect}

Generally, the temperature can be influenced the inhibition efficiency of MVEO for mild steel in a $1 \mathrm{M} \mathrm{HCl}$ solution. This inhibition was performed with and without MVEO optimum concentration $1 \mathrm{~g} / \mathrm{L}$ at a temperature ranging from 303 to $333 \mathrm{~K}$ using weight loss experiments. Table 10 shows the variation of the corrosion rate $\left(W_{\text {corr }}\right)$ and inhibition efficiency $\left(\eta_{\mathrm{WL}} \%\right)$ of the mild steel at different temperatures.

It can be observed clearly from Table 8 that $W_{\text {corr }}$ increases with temperature and the inhibition efficiency $\eta_{W L} \%$ decrease slowly with increasing temperature. Consequently, this could lead to desorption of MVEO from the mild steel surface [21]. 
Table 10. Influence of temperature on the mild steel corrosion at different concentrations in the absence and presence of MVEO at $2 \mathrm{~h}$.

\begin{tabular}{|c|c|c|c|}
\hline \multirow{2}{*}{ Temperature } & \multicolumn{2}{|c|}{ Corrosion rate $W_{\text {corr }}, \mathbf{m g} \cdot \mathrm{cm}^{-2} \cdot \mathbf{h}^{-1}$} & \multirow{2}{*}{$\eta_{\mathrm{WL}} \%$} \\
\hline & blank & MVEO & \\
\hline 303 & 0.8638 & 0.1415 & 83.62 \\
\hline 313 & 1.1526 & 0.2538 & 77.98 \\
\hline 323 & 1.4678 & 0.5369 & 63.42 \\
\hline 333 & 2.3332 & 0.8881 & 61.93 \\
\hline
\end{tabular}

To obtain information on the adsorption process, the activation parameters can be determined from the Arrhenius equation 7 and transition state equation 8:

$$
\begin{gathered}
i_{\text {corr }}=A e^{\left(\frac{-E_{a}}{R T}\right)} \\
i_{\text {corr }}=\frac{R T}{N h} e^{\left(\frac{\Delta S^{*}}{R}\right)} e^{\left(\frac{-\Delta H^{*}}{R T}\right)}
\end{gathered}
$$

Where $A$ being the Arrhenius pre-exponential constant, $E_{\mathrm{a}}$ is the apparent activation energy, $R$ is the gas constant, $T$ is the absolute temperature, $h$ is the Plank's constant, $N$ is Avogadro's number, $\Delta H^{*}$ is the enthalpy of activation and $\Delta S^{*}$ is the entropy of activation.

The Arrhenius plots for the corrosion rate of mild steel are given in Figures 9 and 10. The values of $E_{\mathrm{a}}, \Delta H^{*}, \Delta S^{*}$, and $E_{\mathrm{a}}-\Delta H^{*}$ of MVEO are shown in Table 11.

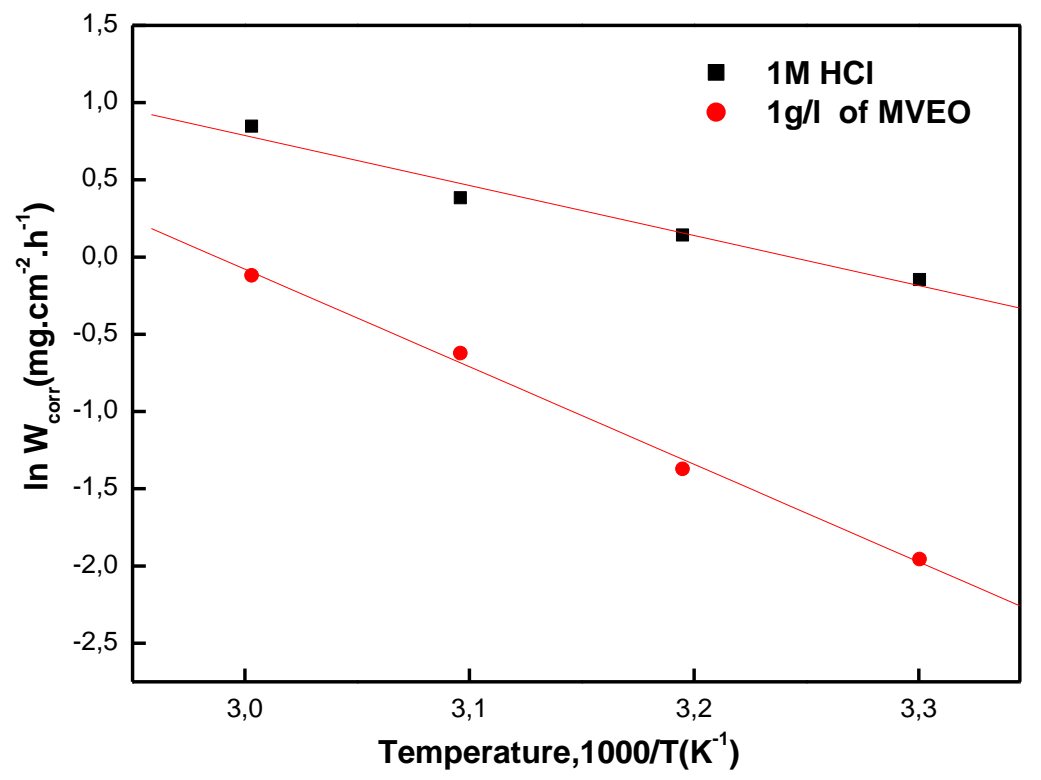

Figure 9. Arrhenius plots $\ln W_{\text {corr }} v s .1000 / \mathrm{T}$ in $1 \mathrm{M} \mathrm{HCl}$ with and without $1 \mathrm{~g} / \mathrm{L}$ of MVEO. 


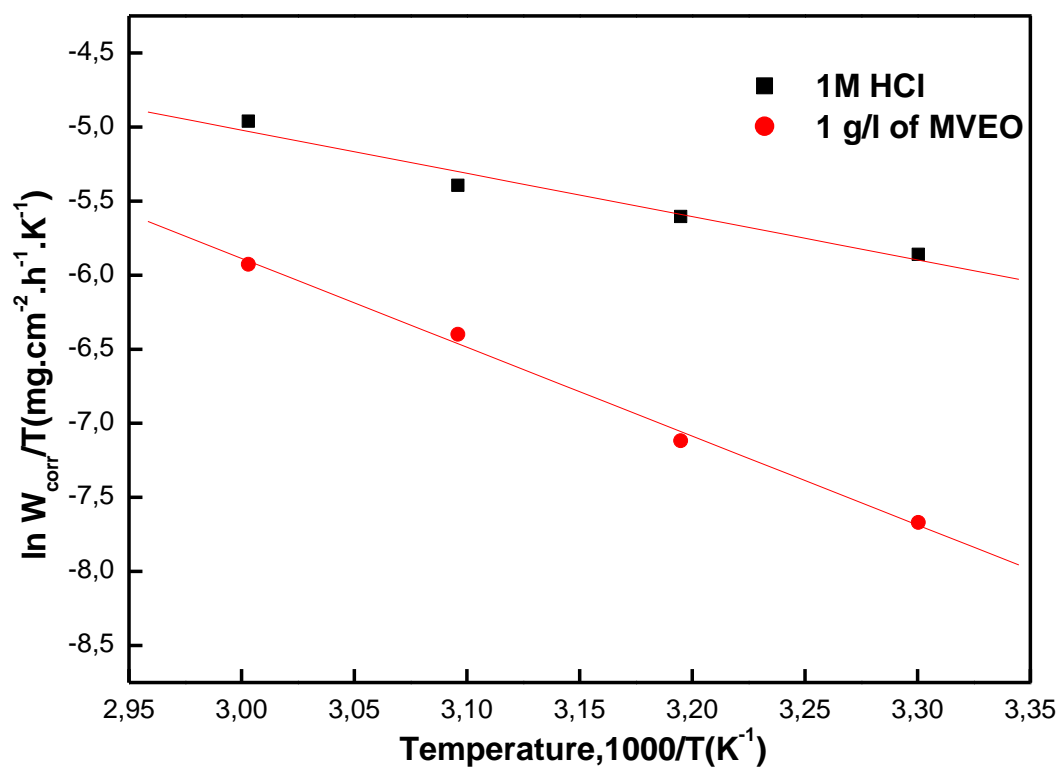

Figure 10. Arrhenius plots $\ln W_{\text {corr }} / \mathrm{T} v s .1000 / \mathrm{T}$ in $1 \mathrm{M} \mathrm{HCl}$ with and without $1 \mathrm{~g} / \mathrm{L}$ of MVEO.

Table 11. The values of $E_{\mathrm{a}}, \Delta H^{*}, \Delta S^{*}$ and $E_{\mathrm{a}}-\Delta H^{*}$ of $\mathrm{MVEO}$ for mild steel in $1 \mathrm{M} \mathrm{HCl}$ in presence and absence of $1 \mathrm{~g} / \mathrm{L}$ of MVEO.

\begin{tabular}{ccccc}
\hline & $\begin{array}{c}\boldsymbol{E}_{\mathbf{a}} \\
\left(\mathbf{k J} \cdot \mathbf{m o l} \mathbf{~}^{\mathbf{1}}\right)\end{array}$ & $\begin{array}{c}\Delta \boldsymbol{H}^{*} \\
\left(\mathbf{k J} \cdot \mathbf{m o l}^{\mathbf{- 1}}\right)\end{array}$ & $\begin{array}{c}\boldsymbol{\Delta} \boldsymbol{S}^{*} \\
\left(\mathbf{J} \cdot \mathbf{m o l}^{-\mathbf{1}} \cdot \mathbf{K}^{-\mathbf{1}}\right)\end{array}$ & $\begin{array}{c}\boldsymbol{E}_{\mathbf{a}}-\boldsymbol{\Delta} \boldsymbol{H}^{*} \\
\left(\mathbf{k J} \cdot \mathbf{m o l}^{-\mathbf{1}}\right)\end{array}$ \\
\hline Blank & 26.95 & 24.31 & -178.42 & 2.64 \\
$1 \mathrm{~g} / \mathrm{L}$ of MVEO & 52.55 & 49.92 & -108.82 & 2.64 \\
\hline
\end{tabular}

We notice from Table 9 that the activation energy $E_{\mathrm{a}}$ of the inhibited solution increases in the presence of MVEO compared to blank solution; this is explained by the specific interaction between the essential oil and the surface of the mild steel. Moreover, the higher value of the activation energy in the presence of MVEO compared to $1 \mathrm{M} \mathrm{HCl}$ solution is often interpreted in the literature by the physisorption of the inhibitor on the mild surface $[32,33]$. The positive values of $\Delta H^{*}$ describe that the dissolution reaction is an endothermic process. Also, it can be observed that the high negative value of $\Delta S^{*}$ in the presence of MVEO reflects a decrease of the disorder during the formation of the complex metal/adsorbed compound [34].

The relationship between $E_{\mathrm{a}}$ and $\Delta H^{*}$ values resulted in a constant value equal to $2.64 \mathrm{~kJ} \cdot \mathrm{mol}^{-1}$.

$$
E_{\mathrm{a}}-\Delta H^{*}=R T
$$




\subsection{Quantum calculations}

In favour to get more detail about the interaction of MVEO with the metallic surface, the DFT calculations for the carvone, the limonene and the 1,8-cineoleas major components of this essential oil were carried out, at B3LYP/6-31G(d,p), in gas and aqueous phases.

According to the quantum computation results, the absence of imaginary frequency in the vibrational spectra prove that the equilibrium structures correspond to the minima of total energy $E_{\mathrm{T}}$ of the investigated components, which implies that the obtained calculated structures correspond to the optimized final geometries of these molecules, as represented in Figure 11.

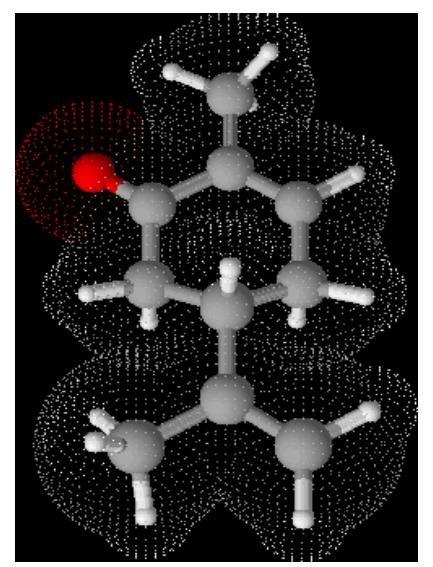

Carvone

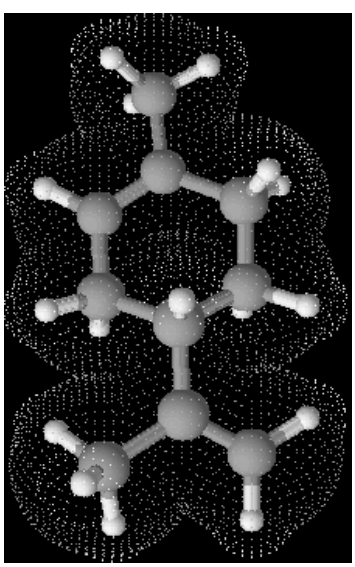

Limonene

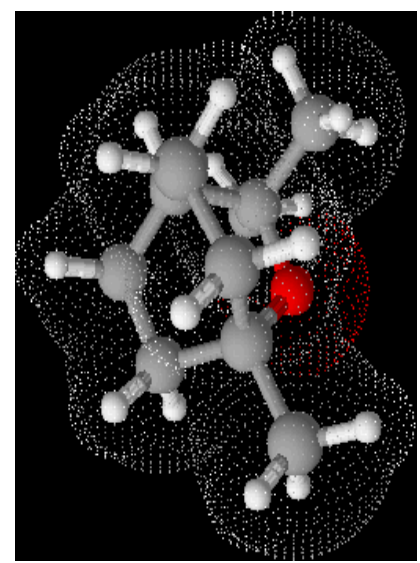

1,8-cineole

Figure 11. The optimised geometries for major components of MVEO, at B3LYP/6$31 \mathrm{G}(\mathrm{d}, \mathrm{p})$, in gas phase.

Furthermore, the pertinent quantum chemical parameters of the three major components derived from the ground state for the optimized geometries of the investigated essential oil were calculated and summarized in Table 12.

Table 7. Quantum chemical descriptors of carvone, limonene and 1,8-cineole structures using DFT at B3LYP/6-31G (d, p) level of theory, in gas $(\mathrm{G})$ and aqueous (A) phases.

\begin{tabular}{ccccccccccc}
\hline Inhibitor & Phase & $\begin{array}{c}\boldsymbol{E}_{\mathbf{T}} \\
(\mathbf{a . u} .)\end{array}$ & $\begin{array}{c}\boldsymbol{E}_{\text {Hомо }}(\mathbf{e V}) \\
\text { Carvone }\end{array}$ & $\begin{array}{c}\boldsymbol{E}_{\mathbf{L U M O}} \\
(\mathbf{e V})\end{array}$ & $\begin{array}{c}\boldsymbol{\Delta} \boldsymbol{E} \\
(\mathbf{e V})\end{array}$ & $\begin{array}{c}\boldsymbol{\mu} \\
(\mathbf{D})\end{array}$ & $\begin{array}{c}\boldsymbol{\chi} \\
(\mathbf{e V})\end{array}$ & $\begin{array}{c}\boldsymbol{\eta} \\
(\mathbf{e V})\end{array}$ & $\begin{array}{c}\boldsymbol{\sigma} \\
\left(\mathbf{e V}^{-1}\right)\end{array}$ & $\boldsymbol{\Delta} \boldsymbol{N}$ \\
& $\mathrm{G}$ & -464.715 & -6.414 & -1.247 & 5.167 & 2.927 & 3.830 & 2.583 & 0.387 & 0.614 \\
Limonene & $\mathrm{A}$ & -464.723 & -6.524 & -1.328 & 5.196 & 4.234 & 3.926 & 2.598 & 0.385 & 0.592 \\
& $\mathrm{G}$ & -390.699 & -6.134 & -0.742 & 5.392 & 0.560 & 3.438 & 2.696 & 0.371 & 0.661 \\
$\begin{array}{c}1,8- \\
\text { Cineole }\end{array}$ & $\mathrm{A}$ & -390.702 & -6.117 & -0.733 & 5.384 & 0.705 & 3.425 & 2.692 & 0.371 & 0.664 \\
\hline
\end{tabular}


In order to give additional indications on the possibility of electron transfer between our molecules and the metal surface, and to determine the electron-rich sites in the studied major components of MVEO, quantum molecular modelling was carried out, which allowed to extract the most relevant molecular reactivity parameters for these three molecules.

A good corrosion inhibitor is one which has a high tendency to donate and receive electrons, in order to bind strongly to the metal surface. By this means, the analysis of the Table 12 indicates that the presence of an oxygen atom in carvone and 1,8-cineole, provokes a higher value of $E_{\mathrm{HOMO}}$ and a lower value of $E_{\mathrm{LUMO}}$ for these compounds compared to limonene, either in gas or aqueous phases. Indeed, the frontier molecular orbitals HOMO and LUMO provide an idea about the sites of the molecule with the tendency to donate or accept electrons [35]. According to this theory, these two molecules can exchange electrons with the metal surface by increasing their coverage rates on it, resulting in enhanced their corrosion inhibition efficiency compared to 1,8-cineole. As result is supported by the energies gap ( $\left.\triangle E=E_{\mathrm{LUMO}}-E_{\mathrm{HOMO}}\right)$ values. The results as indicated in Table 12 follow the order: $\Delta E$ (1,8-cineole) $<\Delta E$ (carvone) $<\Delta E$ (limonene). Chemically, when $\Delta E$ decreases, the molecular reactivity increases; which means that 1,8-cineole and carvone in a second degree, could have better interaction performance with the surface of mild steel, as corrosion inhibitors, more than the limonene molecule.

Concerning the dipole moment $(\mu)$ and electronegativity $(\chi)$, it is well known that a high value of these parameters probably increases the adsorption of the chemical compound on the metal surface [36,37], which increases the contact surface between the molecule and the metal, thus enhancing the capacity of the corrosion inhibition of the said inhibitor. According to the values collected in Table 12 the high values of these two indices for 1,8cineole and carvone compared to limonene, could be attributed to the existence of the oxygen atom in these two compounds, which increases their polarity and facilitates the electrostatic interaction happens between the electric field resulting from the charged metal surface and the electric moments of the two inhibitor molecules and probably, contributes to a better adsorption by affecting the process of the charge transfer through the adsorbed layer [38, 39].

Similarly, it can be also observed that the absolute hardness $(\eta)$ and the softness $(\sigma)$ evolve in the same trend as the other parameters, which is consistent with the meaning of these two parameters. This implies that 1,8-cineole and carvone are less hard and softer than limonene, which translates into their low values from $\Delta E$ which can give them a better reactivity and increase their ability to inhibit the degradation of the metal under study [40].

The electronic density distributions of the HOMO and LUMO orbitals are shown in Figure 12.

As shown in Figure 12, it can be seen from the distribution of the HOMO and LUMO orbitals of the three studied compounds, that the electronic cloud is mainly localized on the benzene rings and on the oxygen atom. Therefore, these molecular sites can be preferentially adsorbed on the surface of the steel. The analysis of the graphs shows also that the red zones assigned to the oxygen atoms correspond to the nucleophilic property, whereas, the blue zones correspond to the electrophilic property. These atoms are very clear on the orbitals of 
1.8-cineole and the carvone; indicating that these two molecules can easily form a coordination bonds with iron atoms compared to limonene, which may enhance the adsorption stability and led to an improvement in the inhibition potential of the comparative molecules.

Furthermore, these results can be reinforced by the charge density distribution and localization on the atoms, which provide information on the reactivity sites, as illustrated in Figure 13.

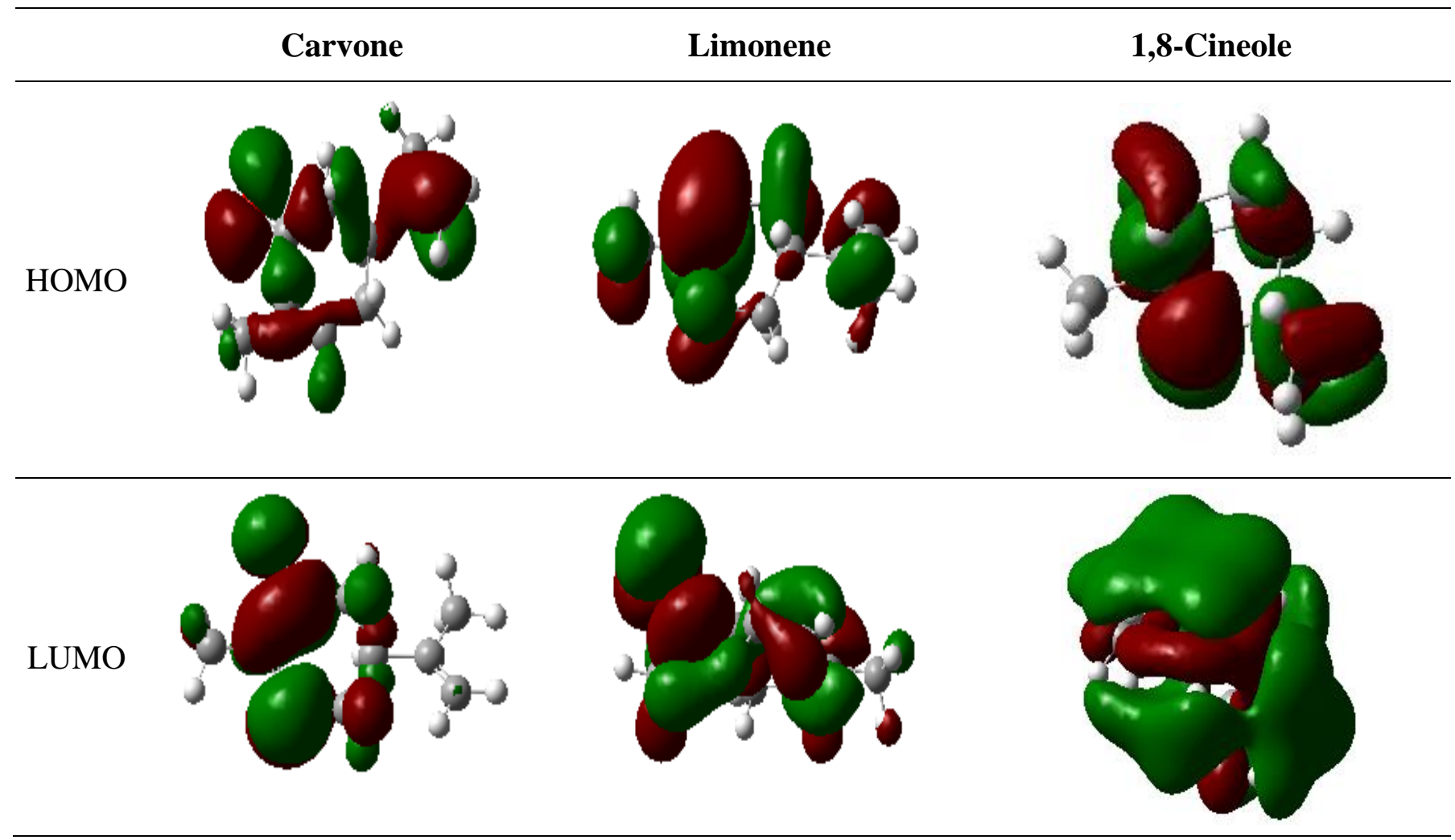

Figure 12. The HOMO and LUMO for carvone, limonene and 1,8-cineole as major components of MVEO, at B3LYP/6-31G (d, p), in gas phase.

According to Figure 13, the mapped data demonstrate that carvone and 1,8-cineole could result in the strong anticorrosion process possibly due to the relatively high surface charge, as compared to limonene. Moreover, the partial atomic charges values in Figure 13 (d, e and f) and their corresponding charge densities displayed by the red areas, in Figure 13 ( $\mathrm{a}, \mathrm{b}$ and $\mathrm{c}$ ) indicate that the $\mathrm{O}$ atoms are more negative charges with $(-0.37 \mathrm{C}$ for 1,8 -cineole and $-0.35 \mathrm{C}$ for carvone), suggesting that these sites are the atoms on which the electrophilic attack would preferably occur $[41,42]$. However, the other partial charges carried by the carbon atoms are generally weakly positive or negative which implies that the sites corresponding to these charges, can probably undergo nucleophilic and electrophilic attacks, thus favoring the percentage of interactions of these three molecules with the steel substrate, and therefore, increasing their corrosion inhibiting capacities. 


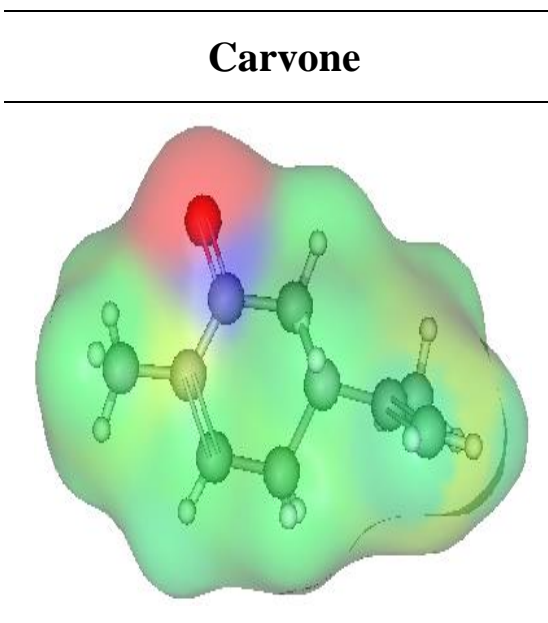

(a)

(d)

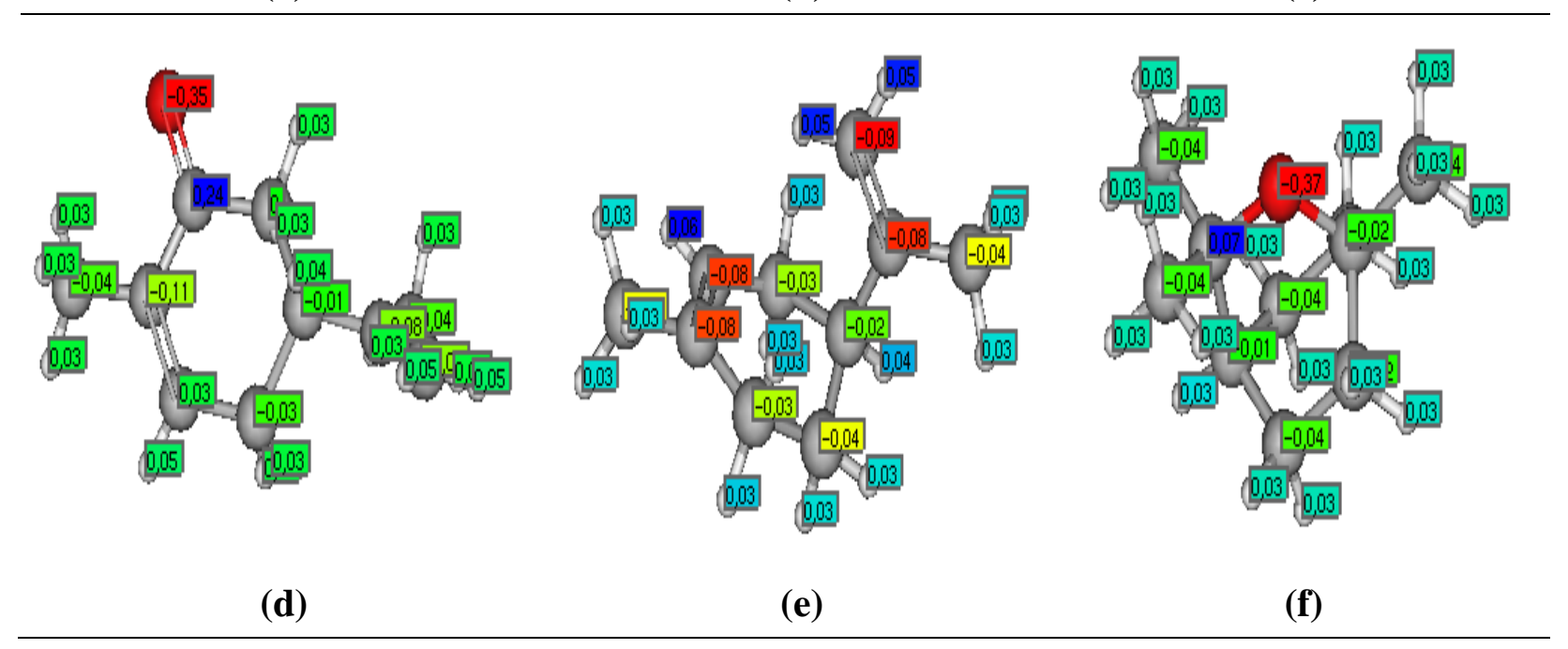

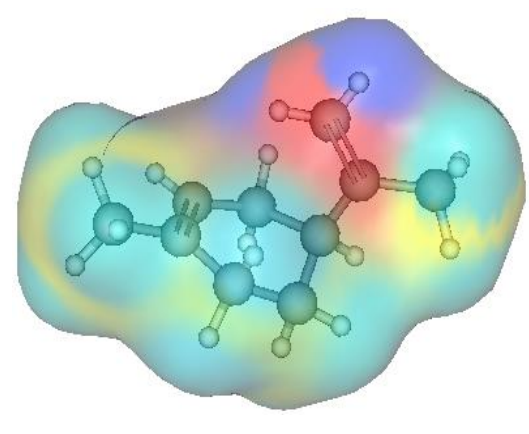

(b)

\section{1,8-Cineole}

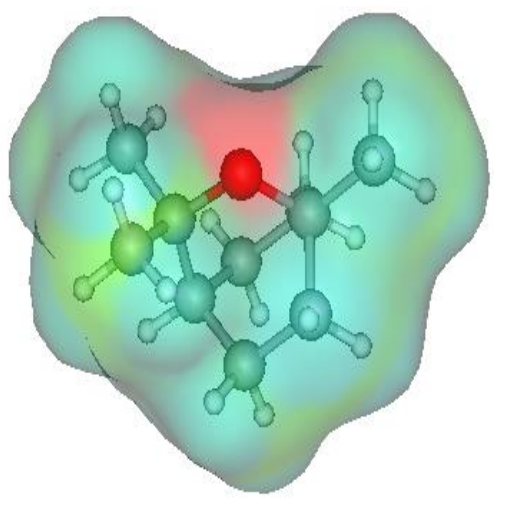

(c)

Figure 13. Charge density distribution and localization on the atoms of the carvone (a and d), the limonene ( $\mathrm{b}$ and $\mathrm{e}$ ) and the 1,8-cineole ( $\mathrm{c}$ and $\mathrm{f}$ ).

\section{Conclusion}

In this research, the Mentha spicata var. viridis L. essential oil (MVEO) was evaluated as a green effective corrosion inhibitor for mild steel in in $1 \mathrm{M}$ hydrochloric acid medium by weight loss measurement, intensity-potential measurements, EIS and DFT calculations. The obtained results lead us to conclude:

- The gravimetric and electrochemical analysis show that Mentha spicata var. viridis L. essential oil (MVEO) is an effective corrosion inhibitor for mild steel in $1 \mathrm{M} \mathrm{HCl}$.

- The inhibition efficiency of MVEO increases with the rise of concentration and reaches $80 \%$ at concentration of $1 \mathrm{~g} / \mathrm{L}$.

- The potentiodynamic polarization curves indicate that MVEO acts as mixed type inhibitor with predominantly anodic. 
- The impedance spectra obtained in the presence of MVEO inhibitor are characterized by two-time constants which attributed to the formation of inhibitory film (high frequencies) and charge transfer (low frequencies).

- The adsorption of MVEO obeys the Temkin adsorption isotherm.

- The thermodynamic parameters analysis reveals that the adsorption of MVEO onto the mild steel surface follows physical adsorption.

- The DFT calculations provide an explanation of the relationship between molecular structure and anticorrosion efficiency, using the structural and electronic properties of carvone, limonene and 1,8-cineole as the major components of the tested Mentha essential oil.

\section{References}

1. R. Salim, E. Ech-chihbi, H. Oudda, F. El Hajjaji, M. Taleb and S. Jodeh, A review on the assessment of imidazole [1,2-a] pyridines as corrosion inhibitor of metals, J. BioTribo. Corros., 2019, 5, 14. doi: 10.1007/s40735-018-0207-3

2. F. El-Hajjaji, I. Merimi, M. Messali, R.J. Obaid, R. Salim, M. Taleb and B. Hammouti, Experimental and quantum studies of newly synthesized pyridazinium derivatives on mild steel in hydrochloric acid medium, Mater. Today: Proc., 2019, 13, 822-831. doi: $\underline{\text { 10.1016/j.matpr.2019.04.045 }}$

3. M. Znini, M. Bouklah, L. Majidi, S. Kharchouf, A. Aouniti, A. Bouyanzer, B. Hammouti, J. Costa and S.S. Al-Deyab, Chemical composition and inhibitory effect of Mentha spicata essential oil on the corrosion of steel in molar hydrochloric acid, Int. J. Electrochem. Sci., 2011, 6, no. 3, 691-704.

4. R.A. Salim, A.B.A. Abu-Goukh, H.E.S. Khalid and G.M. El-Hassan, Effect of Refinery on Spearmint (Mentha spicata var. Viridis 1) Oil Quality, J. Food Process. Technol., 2015, 6, no. 9, 1-6. doi: 10.4172/2157-7110.1000481

5. A. Bouoidina, F. El-Hajjaji, A. Abdellaoui, Z. Rais, M.F. Baba, M. Chaouch, O. Karzazi, A. Lahkimi and M. Taleb, Theoretical and Experimental study of the corrosion inhibition of mild steel in acid medium using some surfactants of the essential oil of Foeniculum Vulgare bulb, J. Mater. Environ. Sci., 2017, 8, 1328-1339.

6. H.D. Dorman, M. Koşar, K. Kahlos, Y. Holm and R. Hiltunen, Antioxidant properties and composition of aqueous extracts from Mentha species, hybrids, varieties, and cultivars, J. Agric. Food Chem., 2003, 51, no. 16, 4563-4569. doi: 10.1021/jf034108k

7. E. McCafferty, Validation of corrosion rates measured by the Tafel extrapolation method, Corros. Sci., 2005, 47, 3202-3215. doi: 10.1016/j.corsci.2005.05.046

8. (a) A.D. Becke, Phys. Rev. A, 1988, 38, 3098; (b) Becke, J. Chem. Phys., 1993, 98, no. $1372,5648$.

9. M.J. Frisch, G.W. Trucks, H.B. Schlegel, G.E. Scuseria, M.A. Robb, J.R. Cheeseman and H. Nakatsuji, (2009) Gaussian 09 (Revision A. 02) [Computer software], Gaussian Inc., Wallingford CT. 
10. E.H. El Assiri， M. Driouch， Z. Bensouda， M. Beniken, A. Elhaloui， M. Sfaira and T. Saffaj, Analytical \& relationship between corrosion inhibition efficiency and derivatives on C-steel surface, Anal. Bioanal. Electrochem., 2019, 11, no. 3, 373-395.

11. M. Yadav, S. Kumar, R.R. Sinha and D. Behera, Experimental and Quantum Chemical Studies on Corrosion Inhibition Performance of Benzimidazole Derivatives for Mild Steel in $\mathrm{HCl}$, Ind. Eng. Chem. Res., 2013, 52, no. 19, 6318-6328. doi: 10.1021/ie400099q

12. X. Zheng, S. Zhang, W. Li, L. Yin, J. He and J. Wu, Investigation of 1-butyl-3-methyl$1 \mathrm{H}$-benzimidazolium iodide as inhibitor for mild steel in sulfuric acid solution, Corros. Sci., 2014, 80, 383-392. doi: 10.1016/j.corsci.2013.11.053

13. E.H. El Assiri, M. Driouch, Z. Bensouda, F. Jhilal, T. Saffaj, M. Sfaira and Y. Abboud, Quantum chemical and QSPR studies of bis-benzimidazole derivatives as corrosion inhibitors by using electronic and lipophilic descriptors, Desalin. Water Treat., 2018, 111, 208-225. doi: $10.5004 /$ dwt.2018.22198

14. E. Ech-Chihbi, A. Nahlé, R. Salim, H. Oudda, F. El Hajjaji, F. El Kalai, A. El Aatiaoui and M. Taleb, An Investigation into Quantum Chemistry and Experimental Evaluation of Imidazopyridine Derivatives as Corrosion Inhibitors for C-Steel in Acidic Media, $J$. Bio- Tribo-Corros., 2019, 5, no. 1, 24. doi: 10.1007/s40735-019-0217-9

15. L. Li, X. Zhang, J. Lei, J. He, S. Zhang and F. Pan, Adsorption and corrosion inhibition of Osmanthus fragran leaves extract on carbon steel, Corros. Sci., 2012, 63, 82-90. doi: 10.1016/j.corsci.2012.05.026

16. R. Salim, A. Elaatiaoui, N. Benchat, E. Ech-chihbi, Z. Rais, H. Oudda, F. El Hajjaji, Y. ElAoufir and M. Taleb, Corrosion behavior of a smart inhibitor in hydrochloric Acid molar: Experimental and theoretical studies, J. Mater. Environ. Sci., 2017, 8, no. 10, 3747-3758.

17. A. Saady, F. El-Hajjaji, M. Taleb, K. Ismaily Alaoui, A. El Biache, A. Mahfoud, G. Alhouari, B. Hammouti, D.S. Chauhan and M.A. Quraishi, Experimental and theoretical tools for corrosion inhibition study of mild steel in aqueous hydrochloric acid solution by new Indanones derivatives, Mater. Discovery, 2019, 12, 30-42. doi: 10.1016/j.md.2018.11.001

18. N. Arrousse, R. Salim, G.A. Houari, F.E. Hajjaji, A. Zarrouk, Z. Rais, D.S. Chauhan and M.A. Quraishi, Experimental and theoretical insights on the adsorption and inhibition mechanism of (2E)-2-(acetylamino)-3-(4-nitrophenyl) prop-2-enoic acid and 4-nitrobenzaldehyde on mild steel corrosion, J. Chem. Sci., 2020, 132, no. 1, 112. doi: 10.1007/s12039-020-01818-w

19. N. Arrousse, E. Mabrouk, B. Hammouti, F. El Hajjaji, Z. Rais and M. Taleb, Synthesis, characterization, anti-corrosion behavior and theoretical study of the new organic dye: 3-oxo-3h-spiro[isobenzofuran-1,9'-xanthene]-3',6'-diylbis(3-methyl-benzenesulfonate), Int. J. Corros. Scale Inhib., 2020, 9, no. 2, 661-687. doi: 10.17675/2305-6894-2020-9$\underline{2-18}$ 
20. S.A. Mrani, S. El Arrouji, K. Karrouchi, F. El Hajjaji, K.I. Alaoui, Z. Rais and M. Taleb, Inhibitory performance of some pyrazole derivatives against corrosion of mild steel in $1.0 \mathrm{M} \mathrm{HCl}$ : Electrochemical, MEB and theoretical studies, Int. J. Corros. Scale Inhib., 2018, 7, no. 4, 542-569. doi: 10.17675/2305-6894-2018-7-4-5

21. I. Langmuir, The constitution and fundamental properties of solids and liquids. Part II.Liquids, J. Franklin Inst., 1917, 184, no. 5, 721. doi: 10.1016/S0016-0032(17)90088-2

22. A.A. El-Awady, Kinetic-Thermodynamic and Adsorption Isotherms Analyses for the Inhibition of the Acid Corrosion of Steel by Cyclic and Open-Chain Amines, $J$. Electrochem. Soc., 1992, 139, no. 8, 2149.

23. E. Ituen, O. Akaranta, A. James and S. Sun, Green and sustainable local biomaterials for oilfield chemicals: Griffonia simplicifolia extract as steel corrosion inhibitor in hydrochloric acid, Sustainable Mater. Technol., 2017, 11, 12-18. doi: 10.1016/j.susmat.2016.12.001

24. A. El Yaktini, A. Lachiri, M. El Faydy, F. Benhiba, H. Zarrok, M. El Azzouzi, M. Zertoubi, M. Azzi, B. Lakhrissi and A. Zarrouk, Inhibitor effect of new azomethine derivative containing an 8-hydroxyquinoline moiety on corrosion behavior of mild carbon steel in acidic media, Int. J. Corros. Scale Inhib., 2018, 7, no. 4, 609-632. doi: 10.17675/2305-6894-2018-7-4-9

25. D.K. Singh, S. Kumar, G. Udayabhanu and R.P. John, 4(N,N-dimethylamino) benzaldehyde nicotinic hydrazone as corrosion inhibitor for mild steel in $1 \mathrm{M} \mathrm{HCl}$ solution: An experimental and theoretical study, J. Mol. Liq., 2016, 216, 738-746. doi: 10.1016/j.molliq.2016.02.012

26. N. Arrousse, R. Salim, Y. Kaddouri, A. Zarrouk, D. Zahri, F. El Hajjaji, R. Touzani, M. Taleb and S. Jodeh, The inhibition behavior of two pyrimidine-pyrazole derivatives against corrosion in hydrochloric solution: Experimental, surface analysis and in silico approach studies, Arabian J. Chem., 2020, 13, no. 7, 5949-5965. doi: 10.1016/j.arabjc.2020.04.030

27. H.H. Zhang and Y.Chen, Experimental and theoretical studies of benzaldehyde thiosemicarbazone derivatives as corrosion inhibitors for mild steel in acid media, J. Mol. Struct., 2019, 1177, 90-100. doi: 10.1016/j.molstruc.2018.09.048

28. F. El Hajjaji, F. Abrigach, O. Hamed, A.R. Hasan, M. Taleb, S. Jodeh, E. RodriguezCastellon, M. del Valle Martinez de Yuso and M. Algarra, Corrosion Resistance of Mild Steel Coated with Organic Material Containing Pyrazol Moiety, Coatings, 2018, 8, no. 10, 330. doi: 10.3390/coatings 8100330

29. M.A.M. Ameer and A.M. Fekry, Corrosion inhibition by naturally occurring Hibiscus sabdariffa plant extract on a mild steel alloy in $\mathrm{HCl}$ solution, Turk. J. Chem., 2015, 39, no. $5,1078-1088$. doi: $10.3906 / \mathrm{kim}-1408-69$

30. E. Ech-chihbi, M.E. Belghiti, R. Salim, H. Oudda, M. Taleb, N. Benchat, B. Hammouti and F. El-Hajjaji, Experimental and computational studies on the inhibition performance of the organic compound "2-phenylimidazo[1,2-a]pyrimidine-3-carbaldehyde" against 
the corrosion of carbon steel, Surf. Interfaces, 2017, 9, 1-29. doi: 10.1016/j.surfin.2017.09.012

31. F. El-Hajjaji, M. Messali, M.V. Martínez de Yuso, E. Rodríguez-Castellón, S. Almutairi, T.J. Bandosz and M. Algarra, Effect of 1-(3-phenoxypropyl) pyridazin-1ium bromide on steel corrosion inhibition in acidic medium, J. Colloid Interface Sci., 2019, 541, 418-424. doi: 10.1016/j.jcis.2019.01.113

32. M. Messali, M. Larouj, H. Lgaz, N. Rezki, F.F. Al-Blewi, M.R. Aouad, A. Chaouiki, R. Salghi and I. Min Chung, A New Schiff Base Derivative as an Effective Corrosion Inhibitor for Mild Steel in Acidic Media: Experimental and Computer Simulations Studies, J. Mol. Struct., 2018, 1168, 39-48. doi: 10.1016/j.molstruc.2018.05.018

33. F. Bentiss and M. Lagrenée, Heterocyclic compounds as corrosion inhibitors for mild steel in hydrochloric acid medium - correlation between electronic structure and inhibition efficiency, J. Mater. Environ. Sci., 2011, 2, no. 1, 13-17.

34. F. El-hajjaji, M. Messali, A. Aljuhani, M.R. Aouad, B. Hammouti and M.E. Belghiti, Pyridazinium-based ionic liquids as novel and green corrosion inhibitors of carbon steel in acid medium: Electrochemical and molecular dynamics simulation studies, J. Mol. Liq., 2018, 249, 997-1008. doi: 10.1016/j.molliq.2017.11.111

35. A.Y. Musa, A.A.H. Kadhum, A.B. Mohamad, A.A.B. Rahoma and H. Mesmari, Electrochemical and quantum chemical calculations on 4, 4-dimethyloxazolidine-2thione as inhibitor for mild steel corrosion in hydrochloric acid, J. Mol. Struct., 2010, 69, no. 1-3, 233-237. doi: 10.1016/j.molstruc.2010.02.051

36. C. Verma, M.A. Quraishi and A. Singh, 5-substituted $1 H$-tetrazoles as effective corrosion inhibitors for mild steel in $1 \mathrm{M}$ hydrochloric acid, J. Taibah Univ. Sci., 2016, 10, 718-733. doi: $10.1016 / \mathrm{j} . j$ tusci.2015.10.005

37. F. El-Hajjaji， E. Ech-chihbi， N. Rezki， F. Benhiba， M. Taleb， D.S. Chauhan and M.A. Quraishi, Electrochemical and theoretical insights on the adsorption and corrosion inhibition of novel pyridinium-derived ionic liquids for mild steel in $1 \mathrm{M} \mathrm{HCl}, J . M o l$. Liq., 2020, 314, 113737. doi: 10.1016/j.molliq.2020.113737

38. N. Anusuya, P. Sounthari, J. Saranya, K. Parameswari and S. Chitra, Quantum Chemical Study on the Corrosion Inhibition Property of Some Heterocyclic Azole Derivatives, Orient. J. Chem., 2015, 31, 1741-1750. doi: 10.13005/ojc/310355

39. Y. Tang, F. Zhang, S. Hu, Z. Cao, Z. Wu and W. Jing, Novel benzimidazole derivatives as corrosion inhibitors of mild steel in the acidic media. Part I: Gravimetric, electrochemical, SEM and XPS studies, Corros. Sci., 2013, 74, 271-282. doi: 10.1016/j.corsci.2013.04.053

40. M.O. Abdulazeez, A.K. Oyebamiji and B. Semire, DFT-QSAR studies on corrosion inhibition efficiency of derivatives of thiadiazole, oxadiazole and triazole, Int. J. Corros. Scale Inhib., 2016, 5, no. 3, 248-262. doi: 10.17675/2305-6894-2016-5-3-5

41. E.H. El Assiri, M. Driouch, J. Lazrak, Z. Bensouda, A. Elhaloui, M. Sfaira, T. Saffaj and M. Taleb, Development and validation of QSPR models for corrosion inhibition of 
carbon steel by some pyridazine derivatives in acidic medium, Heliyon, 2020, 6, no. 10, e05067. doi: 10.1016/j.heliyon.2020.e05067

42. S. Hadisaputra, A.A. Purwoko, I. Ilhamsyah, S. Hamdiani, D. Suhendra, N. Nuryono and B. Bundjali, A combined experimental and theoretical study of (E)-ethyl 3-(4methoxyphenyl) acrylate as corrosion inhibitor of iron in $1 \mathrm{M} \mathrm{HCl}$ solutions, Int. J. Corros. Scale Inhib., 2018, 7, no. 4, 633-647. doi: 10.17675/2305-6894-2018-7-4-10 